\title{
Revisiting Herding Investment Behavior on the Zagreb Stock Exchange: A Quantile Regression Approach
}

\author{
Tihana Škrinjarić ${ }^{*}$ \\ \$Faculty od Economics and Business, University of Zagreb
}

Submitted: July 22, 2018 • Accepted: October 16, 2018

\begin{abstract}
Herding investment behavior on stock markets has consequences for practitioners, theorists, and policy makers. Thus, empirical research on this topic in the last couple of years has grown exponentially. However, there exist only a few papers dealing with herding behavior that consider the Croatian stock market. This study employs the quantile regression approach of estimating several herding investor behavior models of this market for the first time in the literature. Based upon daily data for the 37 most liquid stocks in the Zagreb Stock Exchange (ZSE) for the period September 22, 2014 to May 8, 2018, several model specifications are determined using quantile regression. Because the quantile regression approach deals with specific characteristics of financial data (stylized facts) better than the OLS method, more robust results can be achieved for evaluating if herding behavior is present in the Croatian market. The results indicate very weak to almost nonexistent evidence of herding behavior in the ZSE. Moreover, market volatility does not have any effect on herding behavior. Finally, the economic and political crisis (regarding concern Agrokor) in 2017 was controlled for in the model and the crisis was found insignificant. It seems that herding behavior does not need to be taken into account when tailoring investment strategies on the ZSE.
\end{abstract}

JEL classification: C1, G4, G12

Keywords: herding investor behavior, quantile regression, Agrokor concern crisis, stock market

${ }^{*}$ Corresponding Author. Email: tskrinjar@net.efzg.hr 


\section{Introduction}

In the past 20 years, the research on herding investment behavior has grown exponentially. The studies of Christie and Huang (1995) and Chang et al. (2000) are probably among the most cited papers with empirical research measuring herding behavior as well as estimating its variability under different stock market conditions. The most common approach to empirically evaluating herding behavior in a stock market is ordinary least squares (OLS) estimation using one of several popular models. Newey and West (1987) corrections of the estimated variance-covariance matrix are sometimes made if autocorrelation and/or heteroskedasticity are present in the data. However, OLS estimation, in general, focuses on the expected mean of a dependent variable. On the other hand, characteristics of financial data and financial markets (known as stylized facts) are different from other economic variables (Franses and Dijk, 2000; Guidolin and Pedio, 2018). Thus, OLS estimation is not always the best method of estimating a financial model due to the strong variable distribution assumptions that OLS requires, and because OLS focuses only on the conditional mean. A natural extension to OLS estimation is quantile regression (QR), a semi-parametric method of estimation which evaluates the whole distribution of the dependent variable (not only the mean). QR is robust to outliers in data and asymmetries as well as to non-normality, and it deals with heteroskedasticity in data very well (for a detailed discussion, see Koenker (2005), Davino et al. (2013)). Thus, its popularity has increased for finance applications in the last couple of years because it deals efficiently with characteristics of financial data.

Because herding investment behavior is mostly linked to extreme market movements (detailed results and an overview will be given in the next section), QR can be employed to successfully evaluate the nature of herding behavior in the lower and upper tails of distributions of the dependent variable in the model (see also Lobäo and Serra, 2002; Voronkova and Bohl, 2005; Tan et al., 2008). In this way, detailed insights into investors' behavior can be provided. This is relevant for individual investors and investment funds in order to exploit possible profitable investment strategies, for academic theoreticians and their developments of asset pricing theories, as well as for economic policy makers who try to stabilize the development of financial and stock markets in particular. Existing research on developing stock markets, as well as on Central and Eastern European (CEE) markets, is scarce. The majority of the studies in the literature use OLS in order to estimate simpler forms of the herding behavior model. Only a few exist which apply QR to explore such investment behavior on different markets, and this is especially true for the CEE markets and, in particular, the Croatian market. However, to the best of this author's knowledge, the augmented model of Chiang et al. (2013) has not yet been applied to the Croatian market. ${ }^{1}$

\footnotetext{
${ }^{1}$ The relevance of this model can be seen in the methodology part of the paper.
} 
Another contribution of this study is the comparison of the QR estimates of the coefficients and their confidence bands across quantiles with the OLS estimates. This has rarely been done in the existing literature, and provides immediate insight into whether there are differences between these estimation methods.

Finally, another gap in the literature is the lack of reports of the effect of the Agrokor crisis in Croatia since 2017 on investor herding behavior. Agrokor is one of the biggest concerns in Croatia and South-East Europe. It consists mostly of large retailers, newsstands, meat producers, and agricultural-industrial companies in Croatia. Thus, controversies around this concern, which are still ongoing, have surely affected the Croatian stock market due to several listed Agrokor stocks. ${ }^{2}$ Some of these were suspended from trading in March 2017 due to a sharp decline in their prices as a result of political events at the beginning of that year.

Thus, the purposes of this paper are to empirically evaluate the herding behavior of investors in Croatia, to test for asymmetries in such behavior, and to see if the Agrokor crisis has affected this behavior. The paper is structured as follows. Section 1 reviews previous relevant literature on herding behavior; three subsections explore the theory and its empirical applications in mature and developing markets. Section 2 describes the methodology used in this study. Results of the empirical research are given in Section 3. The last section concludes the paper with recommendations for future research.

\section{Previous Research}

\subsection{Theory of Herding Behavior}

An enormous amount of literature has dealt with the theoretical reasoning behind herding behavior. The most cited research includes studies by Scharfstein and Stein (1990), Devenow and Welch (1996), Cote and Sanders (1997), Bikhchandani et al. (1998), Christie and Huang (1995), Hirshleifer and Teoh (2001), Rook (2006), and Tan et al. (2008). Herding behavior "arises when investors decide to imitate the observed decisions of others or movements in the market rather than follow their own beliefs and information" (Hwang and Salmon, 2004). Some other definitions include "doing what everyone else is doing, even when one's private information suggests doing something else", the obvious intentions of investors to copy the behavior of others, suppressing one's own beliefs and basing investment decisions upon collective actions of the market (Banerjee, 1992; Christie and Huang, 1995). Explicit explanation of herding behavior dates from the works of behavioral economists such as Kahneman, Tversky, and others, but the idea dates back as early as Keynes (1936) who theoretically posited

\footnotetext{
${ }^{2}$ The stocks refer to the companies which Agrokor acquired over the several decades. More details are given in the empirical part of the paper.
} 
that investors would follow others solely because of their fear that contrarian behavior on the market would damage their reputation. However, explanations of this behavior have become more promoted in the late 1990 s and early $2000 \mathrm{~s}^{3}$

The explanations can be divided into two main groups: institutional versus individual investor herding behavior and rational versus non-rational explanations. Institutional investor herding is explained in depth in studies by Shiller and Pound (1989) and Lakonishok et al. (1991, 1992), where it is explained that such investors have more information about each others' trading activities. Moreover, because investment managers are evaluated against one another when decisions are made about their compensations, those managers do not want to be singled out for not having portfolios similar to those of others. Individual herding is explored in Merli and Roger (2013), Barber et al. (2009), and Venezia et al. (2011), where it is noted that herding among individuals is stronger compared to that among institutions as well as being more persistent and highly correlated to market volatility.

However, the vast majority of published studies concern the rational versus non-rational group of explanations. Rational explanations include information-, reputation-, and compensation-based herding. Information-based herding is based on a relative lack or excess of information compared to other market participants (imperfect information) and, basically, that information cascades occur on the market itself (Bikhchandani and Sharma, 2001). ${ }^{4}$ Often, one group starts to follow another group, despite having information which could indicate different outcomes. However, new information shocks can disrupt those cascades. Sometimes, this type of herding is called cascade herding (Devenow and Welch, 1996). In these situations, investors often ignore their own beliefs about future movements of the market.

Reputation-based herding (or principal agent theory-based herding) is based on managers 'staying in the herd' and having similar performance to others because they want to hedge themselves against bad performances on the market. However, by doing so, they also lose above average gain potential (Scharfstein and Stein, 1990). If an individual investor/manager makes a bad investment decision, he/she loses some of his reputation. On the other hand, if a group of investors all make the same bad investment decision, no one is singled out and individual managers are not held responsible. This was discussed by Keynes (1936), who noted that it may be better for one's reputation to fail in a conventional way rather than succeed unconventionally.

Compensation-based herding also refers mostly to managers. Trueman (1994) explains that analysts make similar forecasts to each other based upon already published ones. In

\footnotetext{
${ }^{3}$ See Tversky and Kahneman (1974) for the psychological explanations of herding behavior, where cognitive biases lead to herding behavior because individuals follow ill-judged decisions of a group. See Baddeley (2010) for a detailed review and approach to psychological explanations.

${ }^{4}$ Informed traders actually reveal inside information which others follow (Shleifer and Summers, 1990; Calvo and Mendoza, 2000).
} 
that way, those who have lower abilities just mimic the actions of others in order to get the same results and thus, compensation. Differently said, a manager's performance is measured compared to other professionals in the market. Thus, they are motivated to mimic others in the market in order to receive adequate compensation (Bikhchandani and Sharma, 2001).

Non-rational explanations are often based on psychology. Devenow and Welch (1996) state that investors feel more secure by blindly following others; Lux (1995) uses the expression "contagion of feelings" to explain conformity; Hatfield et al. (1993) and Barsade (2001) found evidence that emotions are contagious and this affects behavior. Some investors follow others and "hide in the herd" due to having a sense of security if they follow the majority (Goldbaum, 2008). Irrational herding is also linked to the theory of noise trading (see DeLong (1990); DeLong et al. (1991)). For further discussion of this topic, see Cote and Sanders (1997), Rook (2006), and Spyrou (2013).

\subsection{Empirical Research Overview: Mature and Developed Mar- kets}

In examining the literature, we see that the early papers empirically evaluated more developed markets such as those in the United States, the United Kingdom, Germany, etc. ${ }^{5}$ A review of this early work can be found in Lobäo and Serra (2007). In the last several years, emerging and frontier markets have been explored as well. Empirical results are divided based on the level of development of the markets examined in the studies. Most of the research uses daily data and the OLS method of estimation (with standard error corrections). Recently, some studies have used methodologies other than the OLS, but not QR approach as well (e.g., Markov switching in Bohl et al. (2013), threshold regression in Saumitra (2012)). The research approaches have included dividing the whole sample into subsections related to the events such as a financial crisis. Moreover, some of the research uses individual investor portfolios and individual stock level data, another part observes sector index data, and still another part uses portfolio and/or investment fund level data. Which type is used depends upon not only data availability, but on the researcher's specific questions as well. Summarized results are given in Table 1, where we see that the original model (defined in formula 3) has been tested in the majority of cases. Depending on the time span used, researchers have found different results and reached conclusions for the same market. However, when herding behavior is found, it is often in more extreme market movements (especially when markets go up).

\footnotetext{
${ }^{5}$ The distinction between developed, developing, and frontier markets has been made based upon suggestions in Chen (2013) and MSCI (Morgan Stanley Capital International) market classification.
} 


\subsection{Empirical Research Overview: Developing and Frontier Mar- kets}

This section will give an overview of recent papers relevant to this study, specifically studies examining CEE and other markets with similar characteristics to the Croatian market. The literature on herding investor behavior today is very large, so the focus here is on that research which is most closely linked to the Croatian market and the application of QR. In recent years, research on developing and emerging markets has grown rapidly. Much research has been focused on Asian markets, due to the Asian financial crisis in the late 1990s. A good overview of the Asian and Latin American markets is given in Chiang and Zheng (2010); on Pacific Basin markets in Chiang et al. (2013); and on different markets around the world in Garg and Gulati (2013) and Chen et al. (2017). Moreover, the theoretical models of Christie and Huang (1995) and Chang et al. (2000) have been extended in recent years: Chiang et al. (2013) add conditional return volatility to the original herding model of Christie and Huang (1995); Yao et al. (2014) modified that original model from 1995 to reduce multicollinearity and heteroskedasticity. New measures of herding behavior have also been developed (Hwang and Salmon, 2004, 2007). The majority of empirical studies have used daily data. Other frequencies are used less often. In some cases, when researchers have included other frequencies, the results indicate herding behavior only in the daily data. See Caporale et al. (2008), for an explanation of these results as a short-term phenomenon.

If we focus on markets similar to Croatia (small, problems with liquidity, emerging CEE markets) and research which employs QR methodology in observing herding behavior, a few conclusions can be drawn. The main findings are summarized in Table 2. We see that the QR method of estimation has emerged only in the last couple of years. The majority of the findings indicate that herding is present in stock markets, especially when the market goes up. However, when comparing estimated parameters across quantiles, herding is found to be an exception, not the rule. This means that the OLS estimation of herding behavior could lead potentially to spurious conclusions across the whole distribution of the herding variable. The Croatian stock market was examined by Pochea et al. (2017) using the QR method and by Škrinjarić and Šego (2018) using maximum likelihood general autoregressive conditional heteroskedasticity (ML-GARCH). The study of Pochea et al. (2017) found that herding in the Croatian market is an isolated phenomenon at the $25 \%$ quantile, with some asymmetries regarding effects of trading volume and volatility on herding behavior. The research of Škrinjarić and Šego (2018) focused only on the Croatian market, implemented 26 different specifications of the model, and confirmed the previous results. However, these two existing studies did not employ some of the models which will be used in this study, nor was there any assessment of the Agrokor crisis. 


\section{Methodology}

Christie and Huang (1995) defined investor herding as the observed cross-sectional dispersion on the stock market as given by:

$$
C S S D_{t}=\sqrt{\frac{1}{n-1} \sum_{j=1}^{n}\left(r_{j, t}-r_{m, t}\right)^{2}}
$$

where $C S S D_{t}$ denotes the cross-sectional standard deviation at time $t, r_{j, t}$ the return on stock $j$ at time $t$, and $r_{m, t}$ the market return at time $t, j \in\{1,2, \ldots, n\}$. The rationale is in the definition of investor herding: investors observe the actions of others and follow them despite their own beliefs. Thus, the dispersion around the market return is small and the measure given in (1) is smaller with greater herding. Chang et al. (2000) redefine the herding measure using the cross-sectional absolute deviation, $C S A D_{t}$ :

$$
C S A D_{t}=\frac{1}{n} \sum_{j=1}^{n}\left|r_{j, t}-r_{m, t}\right|
$$

Most of the recent literature uses the measure given in (2), due to it being more robust to outliers in the data. ${ }^{6}$

The original model of herding behavior is as follows:

$$
C S A D_{t}=\beta_{0}+\beta_{1}\left|r_{m, t}\right|+\beta_{2} r_{m, t}^{2}+\varepsilon_{t}
$$

where it is assumed that in a rational asset pricing model, a linear relationship between market return and $C S A D$ exists (positive value of parameter $\beta_{1}$ ). Moreover, if herding occurs during extreme market movements (denoted with the squared market return), then the value of parameter $\beta_{2}$ should be negative. The variable $\varepsilon_{t}$ is the error term; when estimating model (3) using the OLS method, it is assumed that $\varepsilon_{t} \sim N\left(0, \sigma^{2}\right)$. Because return series are used in the empirical research, this assumption is usually violated. Thus Newey and West (1987) corrections of the variance-covariance matrix of error terms are made, or the GARCH specification is added to the model as well.

Chiang et al. (2013) extended model (3) to the following specification:

$$
C S A D_{t}=\beta_{0}+\beta_{1}\left|r_{m, t}\right|+\beta_{2} r_{m, t}^{2}+\beta_{3} r_{m, t}^{3}+\beta_{4} r_{m, t}^{2} \sigma_{t}^{2}+\varepsilon_{t}
$$

\footnotetext{
${ }^{6}$ The authors based this measure on the conditional CAPM model of Black (1972). Thus, the measure in (2) is the approximation of the expected cross-sectional absolute deviation of the market. As Spyrou (2013) states: "The notion behind this approach is that if herding is present during periods of extreme market conditions, then there should be a less than proportional increase (or even decrease) in the CSAD measure."
} 
where the cubed market returns term, $\beta_{3} r_{m, t}^{3}$, represents the product of the $r_{m, t}^{2}$ and $r_{m, t}$ terms, interpreted as the interaction of herding behavior with the market return. This is based on evidence of and arguments regarding prevailing market returns (DeLong, 1990; DeLong et al., 1991; Sentana and Wadhwani, 1992): positive feedback traders will sell (buy) stocks in a falling (rising) market and the opposite is true for negative feedback traders. This was also observed by Friedman (1953), and other research finds this to be true (Goodfellow et al., 2009; Holmes et al., 2013; Gavriilidis et al., 2013).

The interaction of the squared return and conditional volatility $\left(\sigma_{t}^{2}\right)$ is based upon arguments in Butler and Joaquin (2002) and Forbes and Rigobon (2002): the herding (i.e., cross-market correlations) is smaller when market volatility is small. This was observed empirically, such as in Economoua et al. (2010) and Holmes et al. (2013).

Conditional volatility is estimated in the first step with the GARCH model specification and used in the second step to estimate model (4). If the value of $\beta_{3}$ is positive, then herding is smaller in a downward market; a negative value means that herding is smaller in an upward market. A similar result is interpreted for the value of $\beta_{4}$ (a positive value means that herding decreases as volatility rises and vice versa). Model (4) has not yet been examined on CEE markets, especially Croatian, even without the inclusion of QR methodology.

Yao et al. (2014) defined the following model:

$$
C S A D_{t}=\beta_{0}+\beta_{1}\left|r_{m, t}\right|+\gamma_{1}\left(r_{m, t}-\overline{r_{m}}\right)^{2}+\gamma_{2} C S A D_{t-1}+\varepsilon_{t}
$$

to reduce multicollinearity and autocorrelation, where $\overline{r_{m}}$ is the expected market return.

Binary variables are often added in various specifications of herding models in order to measure asymmetries in bull and bear markets, and to include effects of some shocks such as the global financial crisis of 2007/2008 or some local crisis (such as Agrokor in Croatia). That is why models (4) and (5) will be extended as:

$$
C S A D_{t}=\beta_{0}+\beta_{1}\left|r_{m, t}\right|+\beta_{2} r_{m, t}^{2}+\beta_{3} r_{m, t}^{3}+\beta_{4} r_{m, t}^{2} \sigma_{t}^{2}+\beta_{5} D_{1, t}+\varepsilon_{t}
$$

where

$$
D_{1, t}= \begin{cases}1 & \text { for period March-April 2017 } \\ 0 & \text { otherwise }\end{cases}
$$

The inclusion of the binary variable for up and down markets is not needed in this specification of the model due to the inclusion of the cubed value of market returns and the volatility 
interaction. However, model (5) needs the inclusion of the second binary variable as well:

$$
\begin{aligned}
C S A D_{t} & =\beta_{0}+\beta_{1}\left|r_{m, t}\right|+\left|D_{2, t}+\phi_{1}\right| r_{m, t} \mid\left(1-D_{2, t}\right) \\
& +\gamma_{1}\left(r_{m, t}-\overline{r_{m}}\right)^{2} D_{2, t}+\phi_{2}\left(r_{m, t}-\overline{r_{m}}\right)^{2}\left(1-D_{2, t}\right) \\
& +\gamma_{2} C S A D_{t-1} D_{2, t}+\phi_{3} C S A D_{t-1}\left(1-D_{2, t}\right)+\beta_{5} D_{1, t}+\varepsilon_{t}
\end{aligned}
$$

where

$$
D_{2, t}= \begin{cases}1 & r_{m, t}>0 \\ 0 & \text { otherwise. }\end{cases}
$$

Now, in models (3)-(7), a quantile regression specification is added. Quantile regression has advantages over the least squares method because QR can deal with different types of variable distributions; it does not focus only on the conditional mean of the dependent variable; different effects of variables in the model can be extracted which cannot be done when using OLS; QR is more robust to outliers in data; and, if the data is non-normal, then QR estimates are more precise compared to OLS estimates. We follow Koenker and Bassett (1978), Koenker (2005), and Davino et al. (2013) in describing the methodology. A linear quantile regression model is given by the following:

$$
y_{i}=\beta_{\theta}+\sum_{k=1}^{K} x_{i} \beta_{k}(\theta)+\varepsilon_{i}
$$

where $\beta_{k}(\theta)$ is the $k$-th unknown parameter at the $\theta$-th quantile, $k \in\{0,1, \ldots, K\}$. Model (8) is estimated at the $\theta$-th quantile, $Q_{\theta}(y \mid X), 0<\theta<1$, via the minimization problem given as:

$$
\arg \max _{\beta_{k}(\theta)}\left[\sum_{i: y_{i}<\widehat{y}_{1}}(1-\theta)\left|y_{i}-\beta_{0}(\theta)-\sum_{k=1}^{K} x_{i} \beta_{k}(\theta)\right| \sum_{i: y_{i} \geq \widehat{y}_{i}} \theta\left|y_{i}-\beta_{0}(\theta)-\sum_{k=1}^{K} x_{i} \beta_{k}(\theta)\right|\right] .
$$

We observe that the optimization problem in (9) is a weighted sum of absolute deviations of estimated values from the real ones. The usual procedure to minimize the expression in (9) is by using a linear programming model. The goodness of fit of the model is measured at each quantile with pseudo- $\mathrm{R}$ squared, calculated as the difference between the residual and total absolute sum of weighted deviations:

$$
R_{\theta}^{2}=1-\frac{\sum_{i: y_{i} \geq \widehat{y}} \widehat{\theta}\left|y_{i}-\widehat{y}_{i}\right|+\sum_{i: y_{i}<\widehat{y}_{i}}(1-\widehat{\theta})\left|y_{i}-\widehat{y}_{i}\right|}{\sum_{i: y_{i} \geq \widehat{\theta}} \widehat{\theta}\left|y_{i}-\widehat{\theta}\right|+\sum_{i: y_{i}<\widehat{\theta}}(1-\widehat{\theta})\left|y_{i}-\widehat{\theta}\right|}
$$

Of course, the pseudo-R squared cannot be compared to the regular coefficient of determi- 
nation because the pseudo- $\mathrm{R}$ squared measures goodness of fit only at the $\theta$-th quantile. Because this method is semi-parametric, statistical inference based on estimated values of parameters in the model can be made after a bootstrapping procedure us used to estimate the standard errors of the beta parameters. Two of the most commonly used bootstrapping procedures are the $x y$-pair method and the MCMB (Markov chain marginal bootstrap). The usual Wald test can be conducted to test for any linear hypothesis in the model, including the test for asymmetries across quantiles. Thus, all the herding models described above will be estimated using the QR approach at the following quantiles: 0.01, 0.05, 0.1, 0.25, 0.5, $0.75,0.90,0.95$, and 0.99 . The extreme quantiles are included in order to observe herding behavior in the tails of the herding variable distribution. Because Christie and Huang (1995) state that herding is more prominent during extreme market movements, extreme quantiles are observed to get more insights about these situations. The results are given in the next section.

\section{Empirical Results}

\subsection{Croatian Stock Market Characteristics}

The Croatian stock market is a relatively young market, having started in 1997. Detailed analysis of the legislation and its effects on the Zagreb Stock Exchange (ZSE) is given in Šeba (2017). This research concludes that the legislation did not serve to develop this market and, today, the ZSE is mostly a platform for institutional investors. The value of the official stock market index CROBEX, the total capitalization, and the number of transactions were stagnating until 2003. Afterward, all the series showed an increased growth until the last financial crisis in 2007-2008 (Figures 1 and 2). A mild recovery of the ZSE in 2010 ended the next year, and it has stagnated ever since. Before the financial crisis, the Croatian stock market was bigger than the Romanian and Baltic markets combined (considering market capitalization). This was due to initial public offerings (IPOs) of some of the biggest companies in Croatia (HT, Atlantic Group, Ingra, Magma and Optima; Zagreb Stock Exchange, 2006, 2007, 2008).

Škrinjarić and Besek (2014) analyzed the stock market capitalization within the total capitalization. $^{7}$ The results showed that investors' euphoria and IPOs contributed to the development of the market before the crisis. The stock capitalization showed a negative trend after 2008 and Škrinjarić and Besek (2014) concluded that this was a result of the introduction of new structured securities and investors' prudence (investing more into bonds).

\footnotetext{
${ }^{7}$ Total capitalization includes stock market, bond market and other financial instruments capitalization on ZSE.
} 
Jošić (2006) adds that the beginning of the negotiations with the European Union in the early 2000s have positively affected the development of the market as well. The Croatian market today is shallow. For example, in 2013, the most liquid stocks have constituted almost $60 \%$ of the total market capitalization (the clustering of liquidity is seen only in big company stocks, such as the above mentioned HT and Atlantic group, as well as the IGH institute and Dalekovod).

Another problem is the illiquidity of the market. This is especially true for the period after the crisis. In the last year (2017), the total number of traded securities on the ZSE (including bonds and other types of investments) was 184, with many companies withdrawn from the stock market itself. Vidović (2013) examined whether investors are rewarded for the illiquidity premium on the ZSE. The results of the analysis indicated a negative answer.

\subsection{Data Description}

For the purpose of empirical study of the Croatian market, daily data on prices of 37 stocks and the value of the stock market index, CROBEX, were collected from the Zagreb Stock Exchange (2018) for the period September 22, 2014 through May 8, 2018. The sample is restricted due to using liquid stocks (illiquid stocks are a problem prominent on the Croatian stock market). Because there are not many stocks to choose from on the ZSE, stocks which were traded at least $30 \%$ of the time in the observed period (at least 272 days in total) are used in the sample. If this criterion was higher, e.g., $60 \%$, then only 25 stocks would have been left in the analysis. For the value of $75 \%$ only 17 stocks would be used, and there would be only 9 stocks that were traded at least $90 \%$ of the time. Thus, when the ZSE is being empirically evaluated (regardless of the area which is being researched), the usual practice is to pick the liquid stocks which have been most frequently traded. The stock market return is constructed based on stocks which constituted the index CROBEX in each official revision. This means that not all the 37 stocks constituting this index are in the whole sample. Returns for each stock price were calculated as continuous returns. The $C S A D_{t}$ value was calculated as defined in formula (2). The augmented Dickey-Fuller (ADF) and Zivot-Andrews structural unit root tests were performed for the deviation variable and market return series. All the tests (also controlling for the drift, and for the drift and trend) reject the hypothesis of unit root (with a structural break in the case of the Zivot-Andrews test). ${ }^{8}$ The conditional variance of the market returns was estimated using a GARCH $(1,1)$ process with the assumption of Student's distribution and an ARMA $(1,1)$ process of market return series. ${ }^{9}$ A binary variable was constructed in order to control for the Agrokor crisis,

\footnotetext{
${ }^{8}$ Detailed results are available upon request.

${ }^{9}$ The specification of $\operatorname{ARMA}(1,1)-\operatorname{GARCH}(1,1)$ was chosen based upon the diagnostics of the model. Detailed results are available upon request.
} 
which became publicly prominent at the beginning of March 2017. Agrokor's stocks were delisted from the Zagreb Stock Exchange at the end of April 2017. Thus, the first binary variable is equal to 1 for the period from March 1, 2017 to April 30, 2017 and 0 otherwise. The second binary variable was constructed to control for the market going up or down, with the variable being equal to 1 if the market return is greater than 0 on day $t$ and 0 otherwise.

Descriptive statistics were determined for the $C S A D$ variable in the observed period to additionally confirm the need for using the QR method. Skewness of the $C S A D$ variable is equal to 18.24 and the Jarque-Bera test rejects the normality hypothesis at the usual levels of significance (test statistic value is equal to 10019.16). The coefficient of autocorrelation for the $C S A D$ variable is equal to 0.58 at lag 1 , and is statistically significant at the usual levels (test value in Ljung-Box test is equal to 313.83). This justifies including the lagged value of the dependent variable, as is done in model (5). Moreover, the QQ-plot of the herding variable and its comparison to the normal distribution confirms the results of the Jarque-Bera test (Figure 3). Additionally, the asymmetry compared to the median value of the $C S A D$ is examined in Figure 4, where it can be seen that major discrepancies exist when comparing the upper and lower tails of the distribution. This justifies the use of QR methodology to explore herding behavior on the Croatian market.

\subsection{The Agrokor Crisis Explained}

Inclusion of the binary variable for the Agrokor crisis is due to the size of this concern and the current political events and problems surrounding it. At the end of 2016, Agrokor employed more than 58,000 people in the Balkan area, with a significant drop to 52,500 people in 2017 (Agrokor 2016, 2018). The spread of Agrokor to other countries in the 2000s was significant, based on acquisitions in Serbia, Bosnia and Herzegovina, Hungary, and leading up to the final bigger acquisition in Slovenia at the beginning of the 2010s.

Controversy among investors arose due to Agrokor's high indebtedness when Slovenia's Mercator was bought in 2014. Through the 2010s, Agrokor's growth and operating profit growth rates were lower than the borrowing rate. The increasing market shares of Lidl and Kaufland (small retailers) were also affecting the total business of this concern. And moreover, the economic crisis lasted in Croatia from 2008 until 2014, which affected the revenues of Agrokor as well (Klepo et al., 2017). At the end of 2016, due to Agrokor's inability to pay back debts, the Croatian Bank for Reconstruction and Development granted it new loans. The public was more concerned at the beginning of 2017, when the credit agency Moody's lowered the rating of Agrokor from B2 to B3 (this was a first major negative news about Agrokor which got public). In February 2017, the rating was lowered once again.

Chain events were triggered afterward, mostly political. These included the appointment of a new extraordinary commissioner for the concern, and new legislation, called lex Agrokor. 
In March 2017, the Croatian government and Agrokor's representatives met regarding the problems. The Speaker of the Croatian Parliament, Božo Petrov, resigned from his position due to his disagreements with the rest of the Parliament and Petrov submitted criminal charges against the Agrokor Management Board. Newspapers got hold of e-mail communications between some members of the Croatian government and Agrokor's top people which exposed that some people in the Government knew what was going on. Since then, more data and information has become available, including that Agrokor used shadow banking (using unsecured bills of exchange; see Klepo et al. (2017)). The Agrokor companies with stocks on the ZSE saw their prices drop significantly in March and April of 2017.

The uncertainty regarding the Agrokor situation spilled over into the ZSE, with the food sector index dropping in value by $45.1 \%$ in 2017 (ZSE, 2018). Some of the greatest decreases in Agrokor stock prices in 2017 were: Ledo (-97.31\%), Jamnica (-97.23\%), Zvijezda (-97.02\%), Pik (-96.3\%), Vupik (-90.89\%), and Tisak (-88.39\%). The transaction volume rose greatly on the ZSE in March due to selling of those stocks: the total volume increased by $41 \%$, and offering volume increased by $37 \%$ because investors wanted to get rid of the stocks. The total market index, CROBEX, dropped in value by $10 \%$ and the revision of the food sector index excluded all of the Agrokor's stocks.

Because of all these problems, Agrokor's stocks were withdrawn from the ZSE at the end of April 2017. Moreover, Hanfa (the Croatian financial services supervisory agency) surveyed what was going on at the ZSE and demanded that trading of those stocks be stopped due to the total macroeconomic effects of Agrokor's crisis (Hanfa, 2017) and the visible effects on factoring companies as well (there was a decrease of $56.5 \%$ in the value of their assets).

Analysis by the Croatian National Bank reveals that the country experienced a slowdown in economic growth in the second quarter of 2017, due to uncertainties around the Agrokor concern, as well as a decrease in consumer confidence in April of that year. The crisis due to the problems surrounding this concern affected the dispersion around the market return, increasing it in March and April 2017. As a result of investors getting rid of Agrokor's stocks and some speculative attacks made on the ZSE, some sectors experienced a significant drop in index values (e.g., food) and some experienced great growth (e.g., tourism).

This research assumes that the Agrokor crisis had a significant impact on the CSAD variable, as well as on herding. This is based on Devenow and Welch (1996) who proposed that herding can be irrational at a single point in time, such as when a large decline in stock prices causes investors to instantly sell stocks in order to avoid great portfolio losses and without having done any analysis of the situation. 


\subsection{Estimated Models Results}

The original model given in equation 3 with the binary variable $D_{1, t}$ was estimated using both OLS and QR methods to obtain initial insights into the relationship between market returns and dispersion. Detailed results are given in Table 8. It can be seen that the linear relationship exists in lower quantiles (up to the median) and, afterward, the coefficient $\beta_{1}$ becomes statistically insignificant. Thus, the $C A P M$ assumption of the linear relationship between risk and return is questionable on the Croatian market. The value of $\widehat{\beta}_{1}$ differs across quantiles: it ranges from 10.327 to -44.239 . However, none of the estimated parameters on different quantiles are significant, meaning that very weak evidence on nonlinearities exist if we observe this model. Finally, the effects of the Agrokor crisis are present only in quantiles from $50 \%$ to $90 \%$ with positive estimated parameters (contributing to greater dispersion around the market return).

A graphical comparison of estimated values of the parameters of model (3) is shown in Figure 4 . The $99 \%$ quantile was excluded because it is significantly different from the other quantiles and it disables the clear visualization of the other quantiles. The full representation of Figure 3 with the 99\% quantile included is given in the appendix in Figures 5 and 6 . Red lines denote the OLS estimation (solid line) with its 95\% confidence bands (dashed lines), and black lines denote the estimates using the QR method. It seems there are no differences between the estimations with OLS and QR on any quantile with the exception of the $95 \%$ and 99\% quantiles. Initially, it could be concluded that there do not exist significant differences between the two methods of estimation for the majority of the quantiles for both variables in the model. However, this original model ignores the effects of different market conditions (bull vs. bear markets), possible autocorrelation, effects of volatility, etc. That is why the QR specifications in equations (6) and (7) of the herding model have been estimated. The results are shown in Table 3, while graphical representations of the parameters are given in the appendix in Figures $7-16$.

By observing Table 3, top panel, regarding model (6), we see that in the OLS specification only the variable cubed market returns was significant (at the $10 \%$ level of significance, indicating borderline significance). Thus, the validity of this model could be questionable from the OLS viewpoint. By adding a richer structure using the QR methodology, several conclusions can be drawn. First, the same variable-the cubed value of market returns, is insignificant for all quantiles. This means that the sign of the market return did not affect herding in the observed period on the ZSE. Parameter $\widehat{\beta}_{3}$ is negative only in the highest quantiles (95\% and 99\%), meaning that at the highest quantiles, the herding behavior is somewhat greater in an upward market (showing a bit more consensus in the market). This is in line with previous results regarding Croatia; however, here we do not find enough statistical evidence in favor of herding. Second, it is noticeable that the interaction effect between 
market return and volatility, $\widehat{\beta}_{4}$, is large for all quantiles, and $\widehat{\beta}_{4}$ has positive values for almost all. Although the sign is in line with previous research (such as Forbes and Rigobon (2002) and Venezia et al. (2011)), the values, once again, are not significant.

The mixed results for the quadratic term of market returns (parameter $\widehat{\beta}_{2}$ ) confirm previous conclusions in literature that this variable cannot by itself capture non-linearity in the model (Kabir, 2018). Finally, the Agrokor crisis has affected herding only at the $50 \%$ and $90 \%$ quantiles, with the effect being positive (values of $\widehat{\beta}_{5}$ ). This could be interpreted more as coincidence rather than actual effect. These results are in line with some previous findings which have also failed to detect herding (Chang et al. (2000) and Caparrelli et al. (2004); Pochea et al. (2017) for Croatia).

The results of the estimating model (7) are given in the lower panel of Table 3. Again, the linear part of the model and the squared term of market returns lead to similar conclusions; they are not significant in the model due to their inability to fully capture the herding behavior in the market (see columns for $\widehat{\beta}_{1}, \widehat{\phi}_{1}, \widehat{\gamma}_{1}$, and $\widehat{\phi}_{2}$ ). Only when the dispersion is quite low (from the 1\% up to the $10 \%$ quantiles), the absolute value of the market return when the market goes down has somewhat (positive) effects on the dispersion. The lagged value of the dispersion variable is the only significant one for all quantiles, regardless of the market conditions (see columns for $\widehat{\gamma}_{2}$ and $\widehat{\phi}_{3}$ ). Although Pochea et al. (2017) estimated the model with the inclusion of the lagged value of the $C S A D$ variable, they did not separate the effects of up and down markets. The novelty in this study is distinguishing those effects when the market is bearish and bullish in order to test if differences exist. Although in the literature a lagged dependent variable is added to reduce autocorrelation in the data, the parameter of that variable can be interpreted as how persistent the behavior of that variable is through time. The column with the parameter $\widehat{\gamma}_{2}$ ) refers to bull markets; bear market conditions are captured in the column with parameter $\widehat{\phi}_{3}$.

Across all quantiles, both parameters are positive, which means a positive autocorrelation exists in herding behavior. Thus, when dispersion on day $t$ is low, it is more likely to be low the next day. To see if the parameters for the bull and bear markets are equal (i.e., a symmetry test), a Wald test was performed for each quantile. The results are given in Table 4. We see that in extreme quantiles of the dispersion variable some persistence exists. Finally, the effect of the Agrokor crisis in such a setting is, again, not significant in the model. This is not unexpected; some research has found that in a crisis period when markets go down there is actually less herding, although this is contrary to many previous findings (see Choe et al. (1999) or Hwang and Salmon (2004)).

Additionally, models with the inclusion of the Agrokor binary variable in interaction with 
the squared market returns were estimated:

$$
C S A D_{t}=\beta_{0}+\beta_{1}\left|r_{m, t}\right|+\beta_{2} r_{m, t}^{2}+\beta_{5} D_{1, t}+\lambda D_{1, t} r_{m, t}^{2}+\varepsilon_{t}
$$

in order to obtain more detailed insights into its effects on herding and the squared market return. The results are shown in Tables 5, 6, and 7. Again, if significant results are found, it is more often an isolated event rather than a rule. Thus, based on the results from models (11)(13), it can be finally confirmed that herding on the ZSE is not prominent in the observed period after controlling for markets going up or down, the autocorrelation, volatility, and sign of the changes of the market return itself.

\section{Conclusion}

Herding investor behavior on stock markets has received more attention in the last 20 years, especially after financial crises, because it affects practitioners, policy makers, and academics. In order to enhance investment strategies to beat the market or to tailor suitable economic policies and theoretical models, studies into investor behavior on stock markets need to be done. The majority of the existing empirical literature focuses on more developed markets and uses simpler methodologies. However, investor behavior is not always simple or rational, and asymmetries in human behavior exist. As there is not much research on the Croatian stock market on this topic, the purpose of this paper was to fill some of the existing gaps in the literature. The main findings in this research include the following: Herding behavior on the Croatian market (as an example of a small, emerging, and illiquid market) is not observed with the models used in this study. It is slightly more visible when the market goes up, with the greatest effect being visible at extreme quantiles, especially at the right tail of the dispersion variable distribution. However, the results are insignificant; the signs of specific parameters change only when going from extremely low to extremely high quantiles.

Due to problems of illiquidity in this market, it is possible that herding is not a common phenomenon on the ZSE. This is in line with the explanations of Devenow and Welch (1996) and previous empirical literature which included Croatia in the analysis. The majority of the examined effects of different variables in the model are not significant, especially around the median and quantiles closer to it. Somewhat different behavior is detected sometimes in some extreme quantiles. However, this can be interpreted as due to chance alone. The only significant behavior was found in the persistence of $C S A D$ variable in markets going up or down. The Agrokor crisis was not found to be significant in affecting herding behavior. This could be because the stocks from that concern were withdrawn so quickly from trading that the effects were not severe. 
Some of the shortfalls of this study include the following. A small sample of stocks was included in the study due to illiquidity problems on the ZSE. Only the Croatian market as a whole was observed. And small markets such as the Croatian one could be affected by other markets' movements such as those of the German and other CEE markets. Thus, future research should include spillover effects on herding behavior as well. Also, more insights can be obtained by observing institutional investors and the structures of their portfolios. Thus, more research is needed in that area in the future.

\section{References}

Ababio, K. A. and Mwamba, J. M. (2017). Test of herding behaviour in the Johannesburg stock exchange: application of quantile regression model. Journal of Economic and Financial Sciences, 10(3):457-474.

Al-Shboul, M. (2013). An Examination of Herd Behavior in the Jordanian Equity Market. International Journal of Economics and Finance, 5(1):234-249.

Arouri, M. E. H., Bellando, R., Ringuedé, S., and Vaubourg, A.-G. (2010). Herding by institutional investors: empirical evidence from French mutual funds. Working Papers hal-00507832, HAL.

Baddeley, M. (2010). Herding, social influence and economic decision-making: sociopsychological and neuroscientific analyses. Philosophical Transactions of the Royal Society of London B: Biological Sciences, 365(1538):281-290.

Banerjee, A. V. (1992). A Simple Model of Herd Behavior. The Quarterly Journal of Economics, 107(3):797-817.

Barber, B., Odean, T., and Zhu, N. (2009). Systematic noise. Journal of Financial Markets, 12(4):547-569.

Barsade, S. G. (2001). The Ripple Effect: Emotional Contagion In Groups. Yale school of management working papers, Yale School of Management.

Bikhchandani, S., Hirshleifer, D., and Welch, I. (1998). Learning from the Behavior of Others: Conformity, Fads, and Informational Cascades. The Journal of Economic Perspectives, 12(3):151-170.

Bikhchandani, S. and Sharma, S. (2001). Comportamiento gregario o de rebaño en los mercados financieros: una reseña. Boletín, 0(1):23-42. 
Black, F. (1972). Capital Market Equilibrium with Restricted Borrowing. The Journal of Business, 45(3):444-55.

Blasco, N. and Ferreruela, S. (2008). Testing Intentional Herding in Familiar Stocks: An Experiment in an International Context. Journal of Behavioral Finance, 9(2):72-84.

Bohl, M. T., Klein, A. C., and Siklos, P. L. (2013). A Markov switching approach to herding. Working paper, Centre for International Governance Innovation.

Butler, K. C. and Joaquin, D. C. (2002). Are the gains from international portfolio diversification exaggerated? The influence of downside risk in bear markets. Journal of International Money and Finance, 21(7):981-1011.

Calvo, G. A. and Mendoza, E. G. (2000). Rational contagion and the globalization of securities markets. Journal of International Economics, 51(1):79 - 113.

Caparrelli, F., D'Arcangelis, A. M., and Cassuto, A. (2004). Herding in the Italian Stock Market: A Case of Behavioral Finance. Journal of Behavioral Finance, 5(4):222-230.

Caporale, G. M., Philippas, N., and Economou, F. (2008). Herding behaviour in extreme market conditions: the case of the Athens Stock Exchange. Economics Bulletin, 7(17):1-13.

Chang, E. C., Cheng, J. W., and Khorana, A. (2000). An examination of herd behavior in equity markets: An international perspective. Journal of Banking and Finance, 24(10):1651-1679.

Chen, T. (2013). Do Investors Herd in Global Stock Markets? Journal of Behavioral Finance, $14(3): 230-239$.

Chen, Y.-C., Wu, H.-C., and Huang, J.-J. (2017). Herd Behavior and Rational Expectations: A Test of China's Market Using Quantile Regression. International Journal of Economics and Financial Issues, 7(2):649-663.

Chiang, T., Tan, L., Li, J., and Nelling, E. (2013). Dynamic Herding Behavior in Pacific-Basin Markets: Evidence and Implications. Multinational Finance Journal, 17(3-4):165-200.

Chiang, T. C. and Zheng, D. (2010). An empirical analysis of herd behavior in global stock markets. Journal of Banking and Finance, 34(8):1911-1921.

Choe, H., Kho, B.-C., and Stulz, R. M. (1999). Do foreign investors destabilize stock markets? The Korean experience in 1997. Journal of Financial Economics, 54(2):227-264. 
Chong, T. T.-L., Liu, X., and Zhu, C. (2017). What Explains Herd Behavior in the Chinese Stock Market? Journal of Behavioral Finance, 18(4):448-456.

Christie, W. G. and Huang, R. D. (1995). Following the Pied Piper: Do Individual Returns Herd around the Market? Financial Analysts Journal, 51(4):31-37.

Cote, J. and Sanders, D. (1997). Herding Behavior: Explanations and Implications. Behavioral Research in Accounting, 19:20-45.

Davino, C., Furno, M., and Vistocco, D. (2013). Quantile regression: theory and applications. John Wiley \& Sons.

DeLong, J Bradford, e. a. (1990). Positive Feedback Investment Strategies and Destabilizing Rational Speculation. Journal of Finance, 45(2):379-395.

DeLong, J. B., Shleifer, A., Summers, L. H., and Waldmann, R. J. (1991). The Survival of Noise Traders in Financial Markets. The Journal of Business, 64(1):1-19.

Devenow, A. and Welch, I. (1996). Rational herding in financial economics. European Economic Review, 40(3-5):603-615.

Economoua, F., Kostakis, A., and Philippas, N. (2010). An Examination of Herd Behaviour in Four Mediterranean Stock Markets. In Proceedings at the European Economics and Finance Society's 9th Annual Conference, 3-6 June 2010. Global Imbalances, Financial Institutions, and Reforms in the Post-crisis Era, Athens, Greece.

Filip, A., Pochea, M., and Pece, A. (2015a). The Herding Behaviour of Investors in the CEE Stocks Markets. Procedia Economics and Finance, 32:307-315.

Filip, A.-M., Pece, A. M., and Pochea, M. M. (2015b). An Empirical Investigation of Herding Behavior in CEE Stock Markets under the Global Financial Crisis. Procedia Economics and Finance, 25:354 - 361 .

Forbes, K. J. and Rigobon, R. (2002). No Contagion, Only Interdependence: Measuring Stock Market Comovements. Journal of Finance, 57(5):2223-2261.

Franses, P. H. and Dijk, D. v. (2000). Non-Linear Time Series Models in Empirical Finance. Cambridge University Press.

Friedman, M. (1953). The Case for Flexible Exchange Rates, in: Essays in Positive Economics,. University of Chicago Press. 
Garg, A. and Gulati, R. (2013). Do investors herd in Indian market. DECISION, 40(3):181196.

Gavriilidis, K., Kallinterakis, V., and Ferreira, M. P. L. (2013). Institutional industry herding: Intentional or spurious? Journal of International Financial Markets, Institutions and Money, 26(C):192-214.

Goldbaum, D. (2008). Coordinated investing with feedback and learning. Journal of Economic Behavior and Organization, 65(2):202-223.

Goodfellow, C., Bohl, M. T., and Gebka, B. (2009). Together we invest? Individual and institutional investors' trading behaviour in Poland. International Review of Financial Analysis, 18(4):212-221.

Guidolin, M. and Pedio, M. (2018). Essentials of Time Series for Financial Applications. Academic Press.

Hatfield, E., Cacioppo, J. T., and Rapson, R. L. (1993). Emotional Contagion. Current Directions in Psychological Science, 2(3):96-100.

Hirshleifer, D. and Teoh, S. H. (2001). Herd Behavior and Cascading in Capital Markets: A Review and Synthesis. MPRA Paper 5186, University Library of Munich, Germany.

Holmes, P., Kallinterakis, V., and Ferreira, M. P. L. (2013). Herding in a Concentrated Market: a Question of Intent. European Financial Management, 19(3):497-520.

Hwang, S. and Salmon, M. (2004). Market stress and herding. Journal of Empirical Finance, $11(4): 585-616$.

Hwang, S. and Salmon, M. (2007). Sentiment and Beta Herding. University of warwick, University of Warwick Working Paper.

Jošić, M. (2006). Utjecaj procesa pregovora Hrvatske s Europskom komisijom na razvoj tržišta dionica u Hrvatskoj (Impact of the Coatia's EU accession on the development of capital market in Croatia). Zbornik Ekonomskog fakulteta u Zagrebu (Proceedings of the Faculty of Economics and Business in Zagreb), Vol. 4, No. 1:131-144.

Kabir, M. H. (2018). Did Investors Herd during the Financial Crisis? Evidence from the US Financial Industry. International Review of Finance, 18(1):59-90.

Kallinterakis, V. and Lodetti, M. (2009). Nonlinearities, Herd Behaviour and Market Illiquidity: Evidence from Montenegro? Economic Analysis, 42(3-4):7-17. 
Keynes, J. M. (1936). The general theory of employment, interest and money. London : Macmillan, 1936.

Khan, H., Hassairi, S., and Viviani, J.-L. (2011). Herd behavior and market stress: The case of four European countries. International Business Research, 4(3):53-67.

Klepo, M., Bićanić, I., and Ivanković, v. (2017). Slučaj Agrokor: Kriza najveće hrvatske kompanije. Friedrich ebert stiftung analysis, Friedrich Ebert Stiftung.

Koenker, R. (2005). Quantile Regression. Cambridge University Press.

Koenker, R. W. and Bassett, G. (1978). Regression Quantiles. Econometrica, 46(1):33-50.

Kremer, S. and Nautz, D. (2011). Short-Term Herding of Institutional Traders: New Evidence from the German Stock Market. Discussion Paper 2011-015, Sonderforschungsbereich 649, Humboldt University, Berlin, Germany.

Lakonishok, J., Shleifer, A., and Vishny, R. W. (1991). Do Institutional Investors Destabilize Stock Prices? Evidence on Herding and Feedback Trading. Working Paper 3846, National Bureau of Economic Research.

Lakonishok, J., Shleifer, A., and Vishny, R. W. (1992). The impact of institutional trading on stock prices. Journal of Financial Economics, 32(1):23 - 43.

Lobäo, J. and Serra, A. (2007). Diversification and Portfolio Management of Mutual Funds. Finance and Capital Markets Series., chapter Herding Behavior: Evidence from Portuguese Mutual Funds, pages 167-197. Palgrave Macmillan, London.

Lobäo, J. and Serra, A. P. (2002). Herding behavior: Evidence from Portuguese mutual funds. Working paper. In Proceedings of the Second Conference of the Portuguese Finance Network.

Lux, T. (1995). Herd Behaviour, Bubbles and Crashes. Economic Journal, 105(431):881-96.

Merli, M. and Roger, T. (2013). What drives the herding behavior of individual investors? Finance, 34(3):67-104.

Mobarek, A., Mollah, S., and Keasey, K. (2014). A cross-country analysis of herd behavior in Europe. Journal of International Financial Markets, Institutions and Money, 32(C):107127.

Newey, W. and West, K. (1987). A Simple, Positive Semi-definite, Heteroskedasticity and Autocorrelation Consistent Covariance Matrix. Econometrica, 55(3):703-08. 
Ouarda, M., Bouri, A. E., and Bernard, O. (2013). Herding Behavior under Markets Condition: Empirical Evidence on the European Financial Markets. International Journal of Economics and Financial Issues, 3(1):214-228.

Pochea, M.-M., Filip, A.-M., and Pece, A.-M. (2017). Herding Behavior in CEE Stock Markets Under Asymmetric Conditions: A Quantile Regression Analysis. Journal of Behavioral Finance, 18(4):400-416.

Pop, R. E. (2012). Herd behavior towards the market index: evidence from Romanian stock exchange. MPRA Paper 51595, University Library of Munich, Germany.

Rook, L. (2006). An Economic Psychological Approach to Herd Behavior. Journal of Economic Issues, 40(1):75-95.

Saastamoinen, J. (2008). Quantile Regression Analysis of Dispersion of Stock ReturnsEvidence of Herd behavior. Discussion Paper 57, University of Joensuu.

Saumitra, B. (2012). A note on the empirical test of herding: a threshold regression approach. MPRA Paper 38037, University Library of Munich, Germany.

Scharfstein, D. and Stein, J. (1990). Herd Behavior and Investment. American Economic Review, 80(3):465-79.

Šeba, M. G. (2017). 20 Years of the Croatian Capital Market. Zagreb International Review of Economics and Business, 20(s1):41-58.

Sentana, E. and Wadhwani, S. B. (1992). Feedback Traders and Stock Return Autocorrelations: Evidence from a Century of Daily Data. Economic Journal, 102(411):415-425.

Shiller, R. and Pound, J. (1989). Survey evidence on diffusion of interest and information among investors. Journal of Economic Behavior and Organization, 12(1):47-66.

Shleifer, A. and Summers, L. H. (1990). The Noise Trader Approach to Finance. Journal of Economic Perspectives, 4(2):19-33.

Škrinjarić, T. and Besek, B. (2014). Pre and post crisis performance measurement of Croatian stock market. Zagreb International Review of Economics and Business, 17(2):97-116.

Škrinjarić, T. and Šego, B. (2018). Exploring herding investment behaviour on Zagreb Stock Exchange. In Proceedings of the ISCCRO - International Statistical Conference in Croatia, pages $146-153$. 
Spyrou, S. (2013). Herding in financial markets: a review of the literature. Review of Behavioral Finance, 5(2):175-194.

Tan, L., Chiang, T., Mason, J. R., and Nelling, E. (2008). Herding behavior in Chinese stock markets: An examination of A and B shares. Pacific-Basin Finance Journal, 16(1-2):61-77.

Tessaromatis, N. and Thomas, V. (2009). Herding behavior in the Athens Stock Exchange. Investment Management and Financial Innovations, 6(3 (cont)):156-164.

Trenca, I., Petria, I., and Pece, A. M. (2015). Empirical inquiry of gregarious behavior: evidence from European emerging markets. Revista Economică, 67(2):143-160.

Trenca, I., Petria, N., and Pece, A. M. (2014). The Herding Behavior on Small Capital Markets: Evidence From Romania. Analele Universitatii din Oradea. Stiinte Economice, $23: 795-801$.

Trueman, B. (1994). Analyst Forecasts and Herding Behavior. Review of Financial Studies, $7(1): 97-124$.

Tversky, A. and Kahneman, D. (1974). Judgment under Uncertainty: Heuristics and Biases. Science, 185(4157):1124-1131.

Venezia, I., Nashikkar, A., and Shapira, Z. (2011). Firm specific and macro herding by professional and amateur investors and their effects on market volatility. Discussion Paper Series dp586, The Federmann Center for the Study of Rationality, the Hebrew University, Jerusalem.

Vidović, J. (2013). Investigation of Stock Illiquidity on Central and South East European markets in Naïve Portfolio Framework. Economic Thought and Practice, 22(2):537-550.

Voronkova, S. and Bohl, M. T. (2005). Institutional Traders' Behavior in an Emerging Stock Market: Empirical Evidence on Polish Pension Fund Investors. Journal of Business Finance and Accounting, 32(7-8):1537-1560.

Yao, J., Ma, C., and He, W. P. (2014). Investor herding behaviour of Chinese stock market. International Review of Economics and Finance, 29:12 - 29.

Zagreb Stock Exchange (2006-2017). Yearly and quarterly reports. available at http://www.zse.hr [accessed on october 2, 2018], Zagreb Stock Exchange.

Zhou, J. and Anderson, R. (2013). An Empirical Investigation of Herding Behavior in the U.S. REIT Market. The Journal of Real Estate Finance and Economics, 47(1):83-108. 
Figure 1: Value of Market Index CROBEX on the ZSE

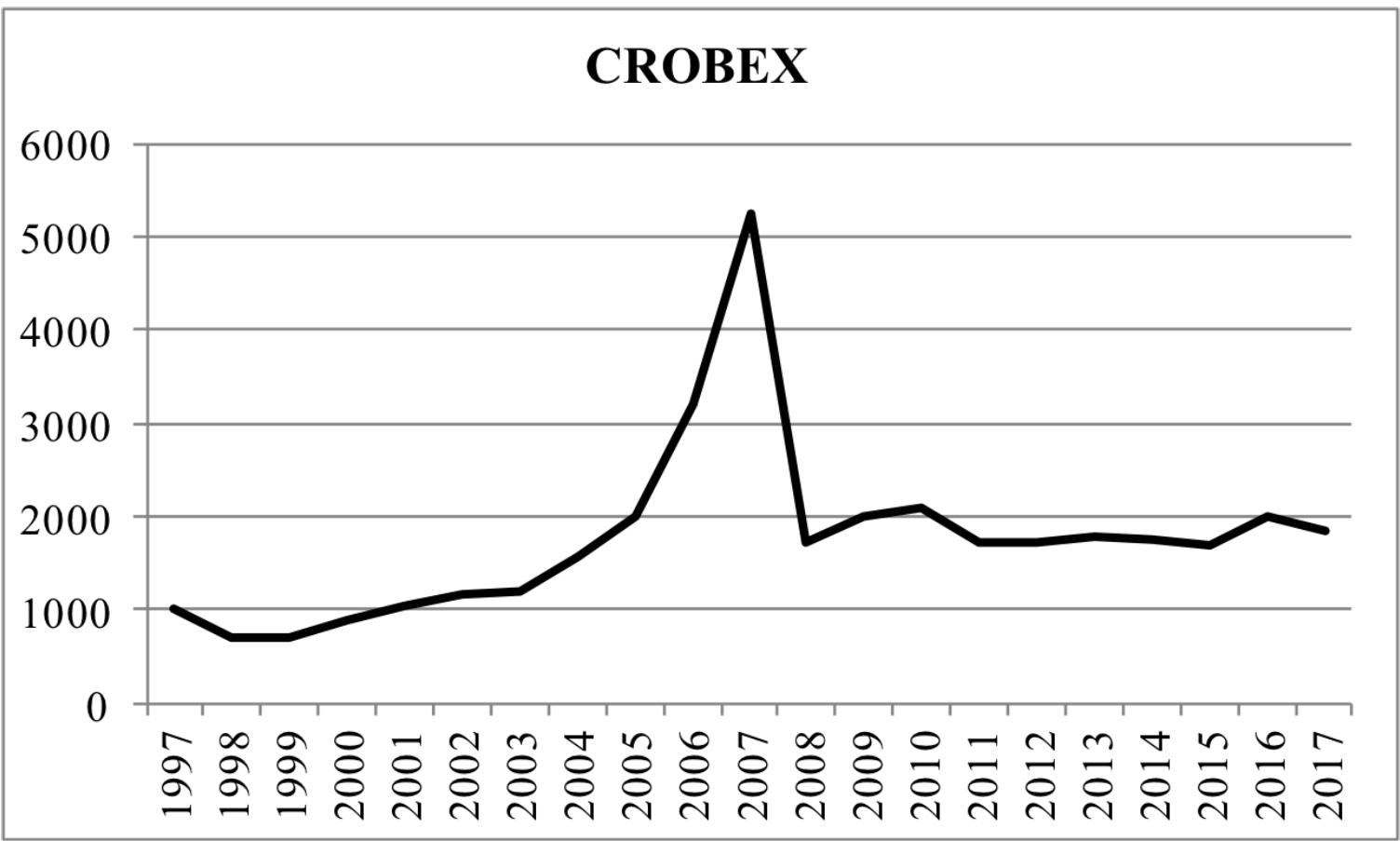

Figure 2: Total Market Capitalization and Number of Transactions on the ZSE

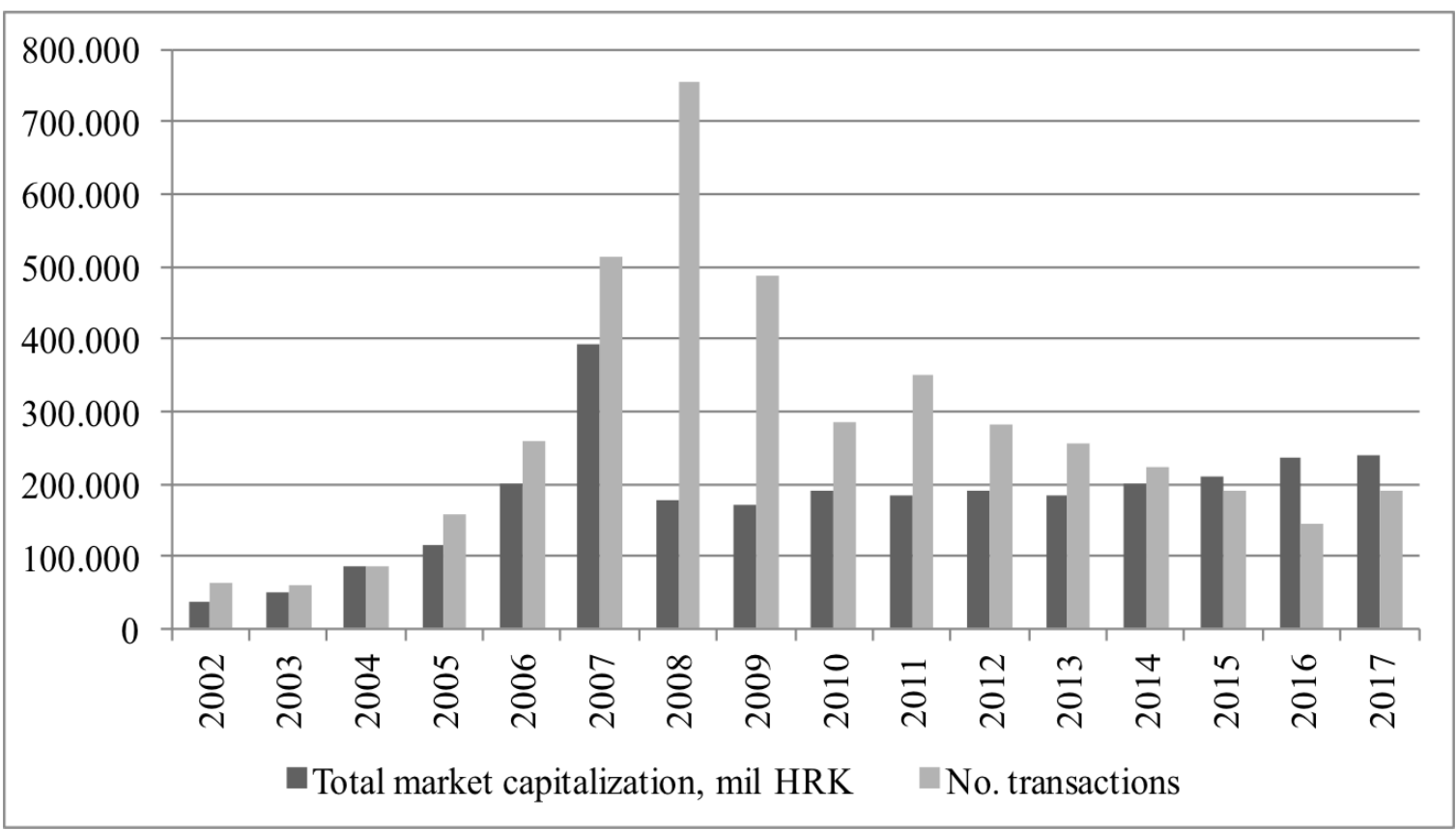


Figure 3: QQ plot of the CSAD, compared to the normal distribution (3a, left); QQ plot of CSAD, asymmetry compared to median (3b, right)
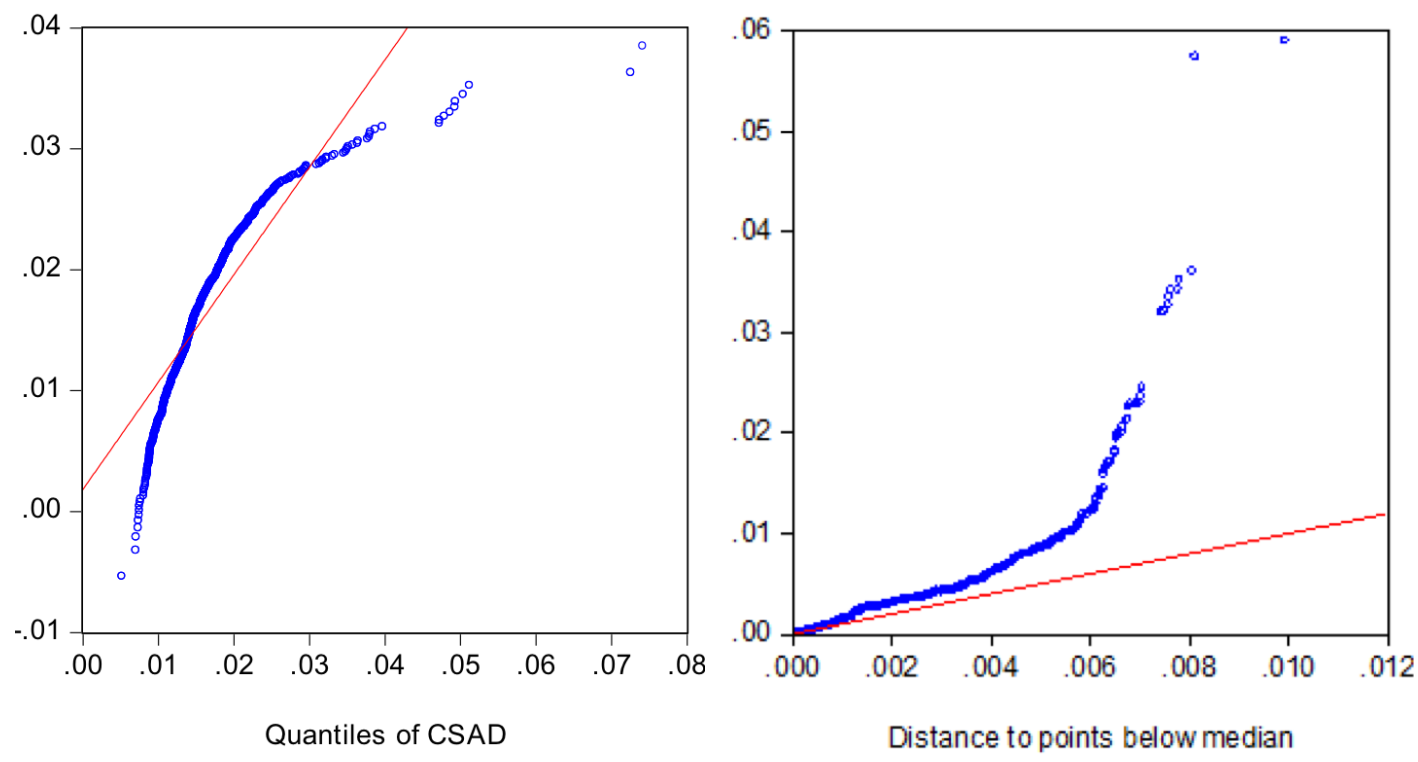

Figure 4: Comparison of estimated values of parameters from model, OLS vs. QR method, parameter $\hat{\beta}_{1}$ in left panel, parameter $\hat{\beta}_{2}$ in right panel
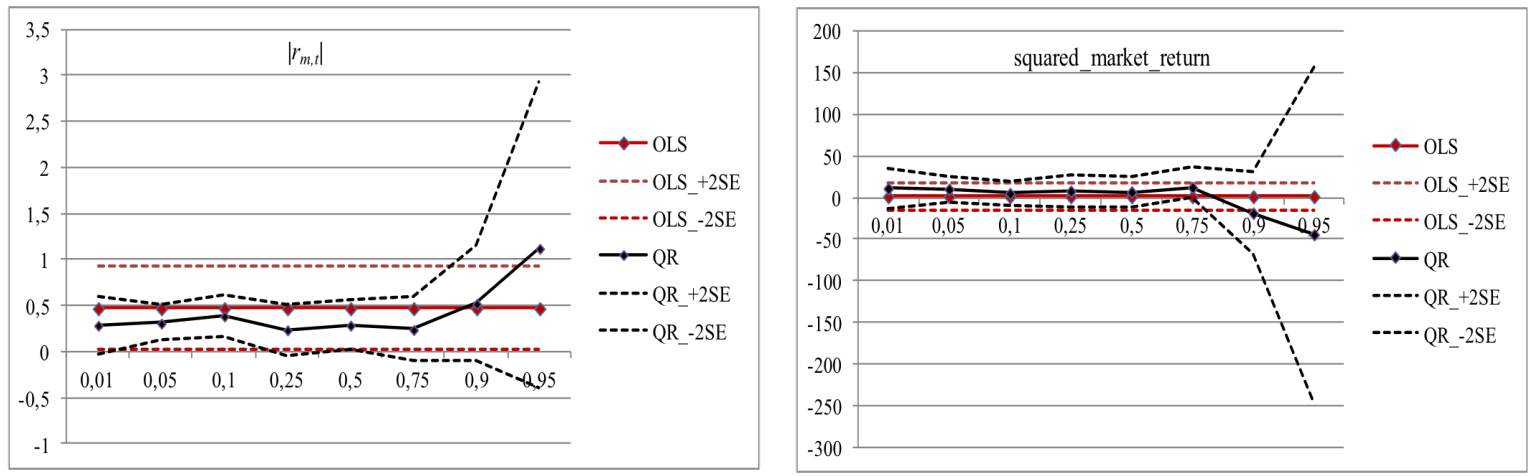
Figure 5: Comparison of estimated values of parameter $\hat{\beta}_{1}$ from model (3), OLS vs. QR method

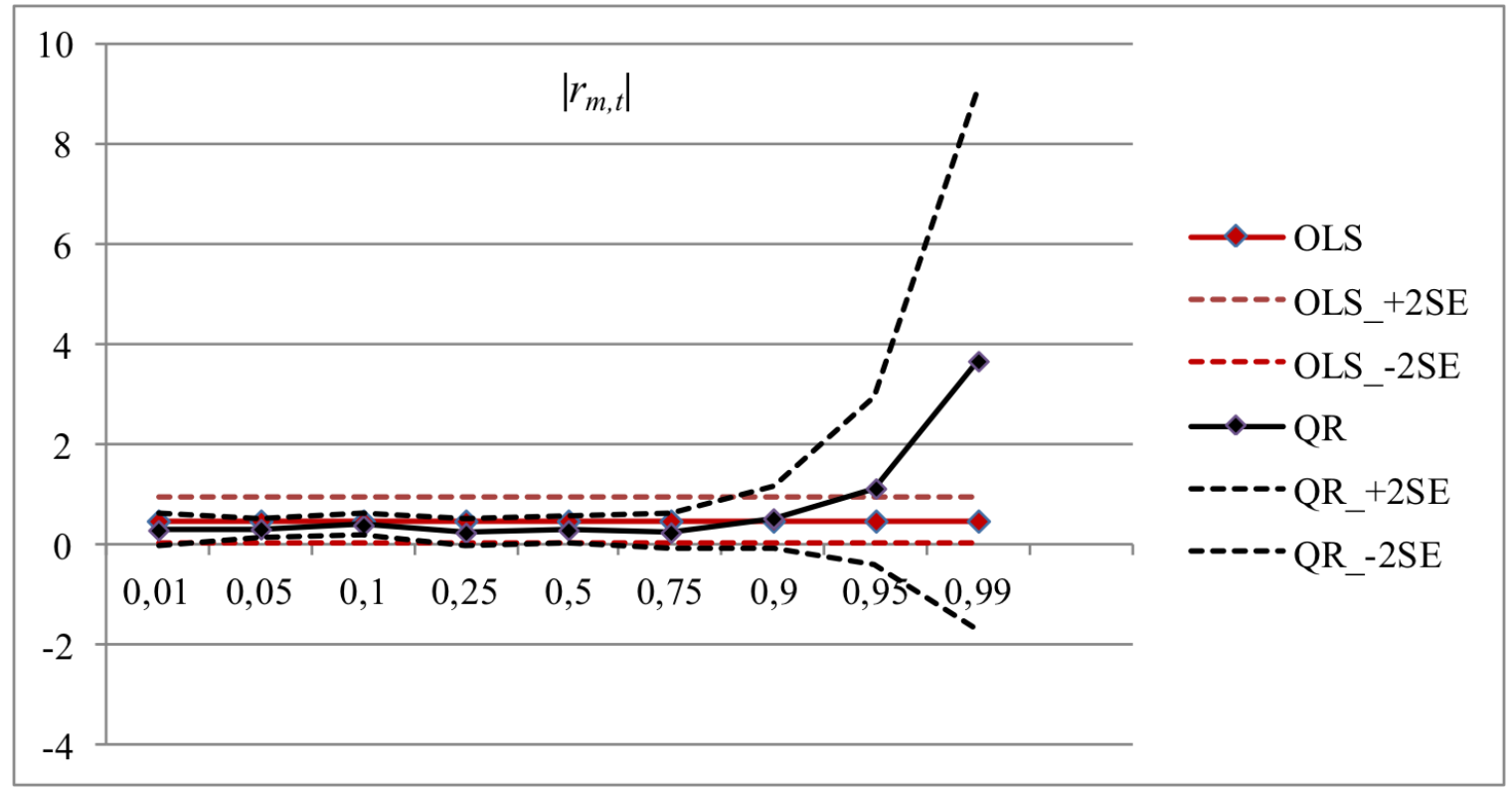

Figure 6: Comparison of estimated values of parameter $\hat{\beta}_{2}$ from model (3), OLS vs. QR method

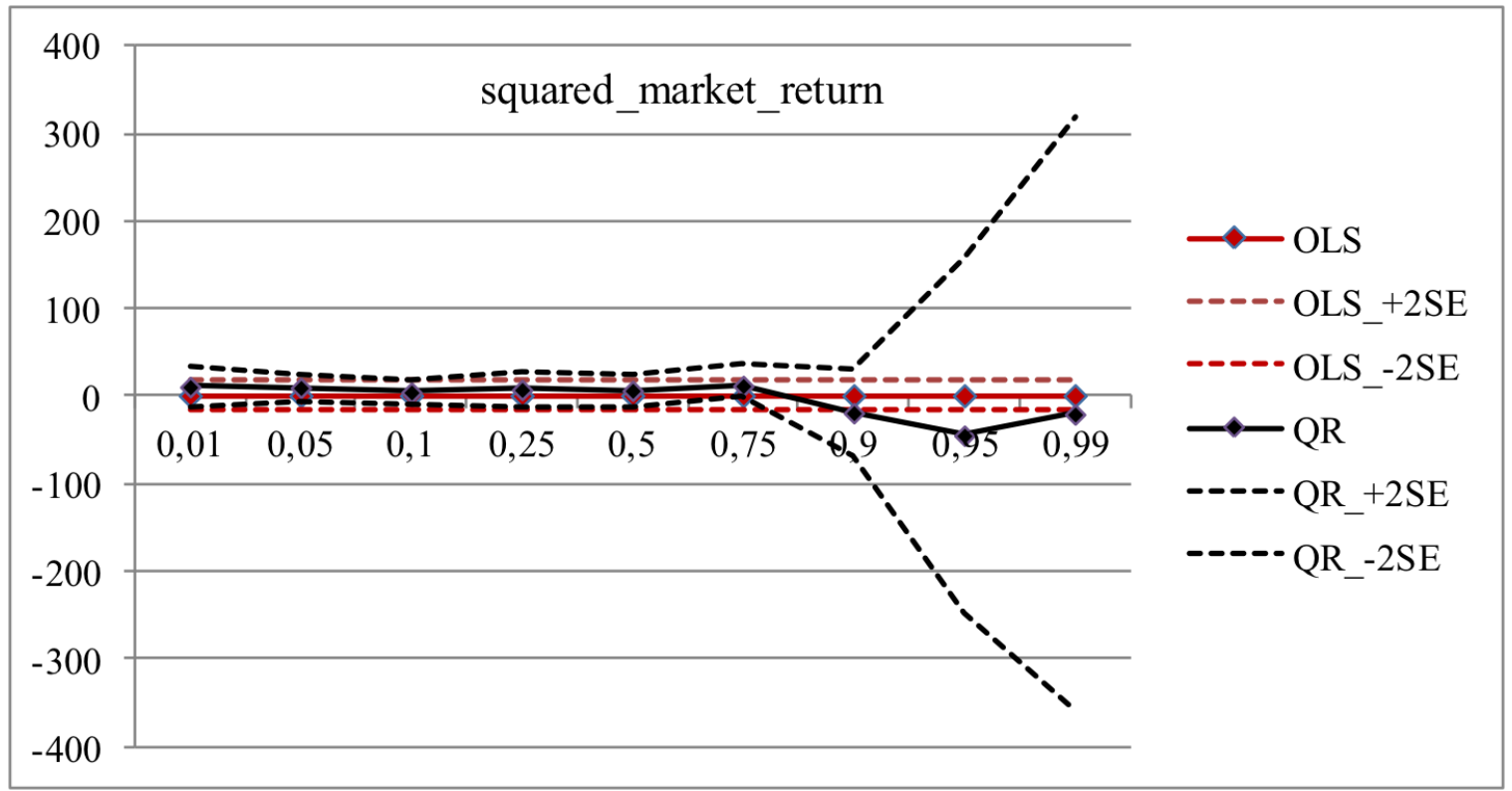


Figure 7: Comparisons of estimated values of parameter $\hat{\beta}_{1}$ from model (6), OLS vs. QR method

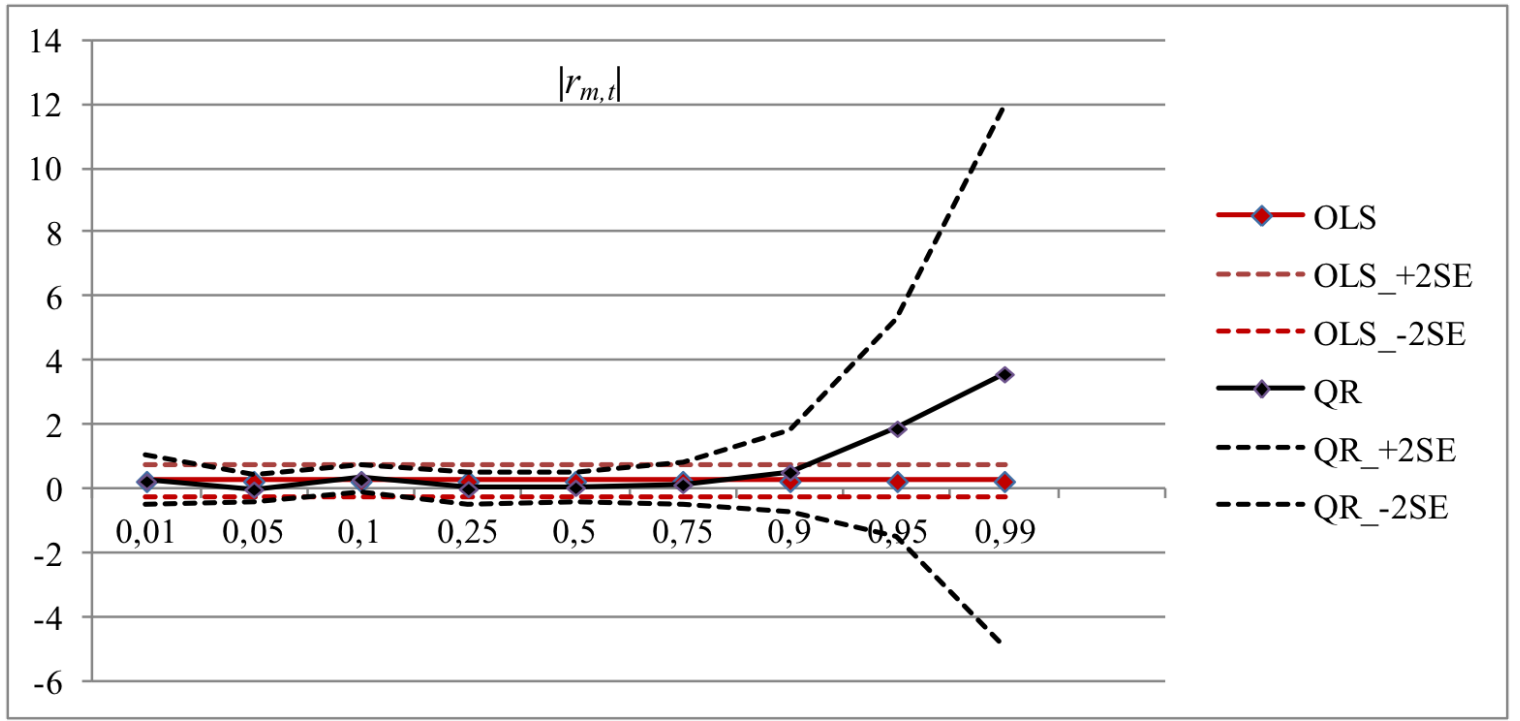

Figure 8: Comparison of estimated values of parameter $\hat{\beta}_{2}$ from model (6), OLS vs. QR method

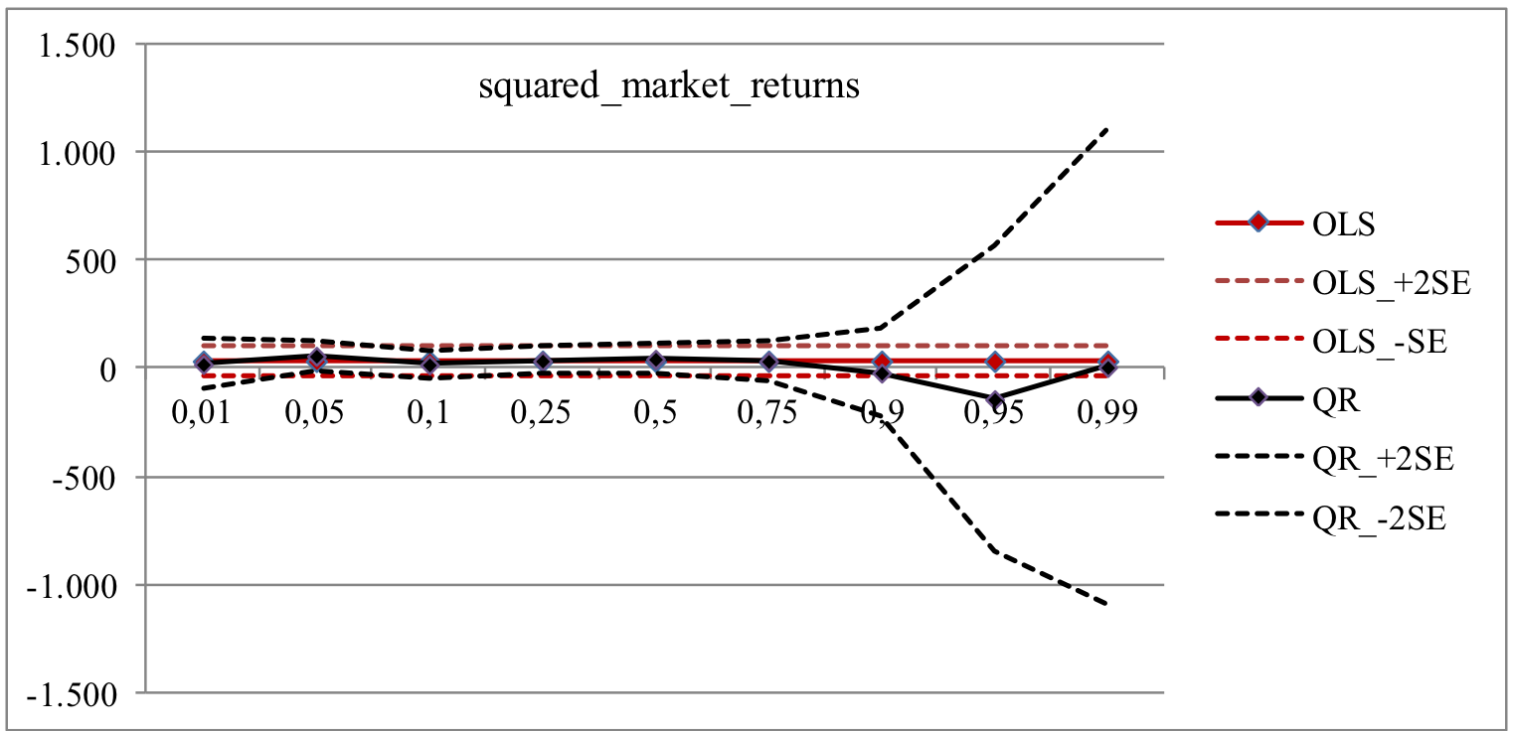


Figure 9: Comparison of estimated values of parameter $\hat{\beta}_{3}$ from model (6), OLS vs. QR method

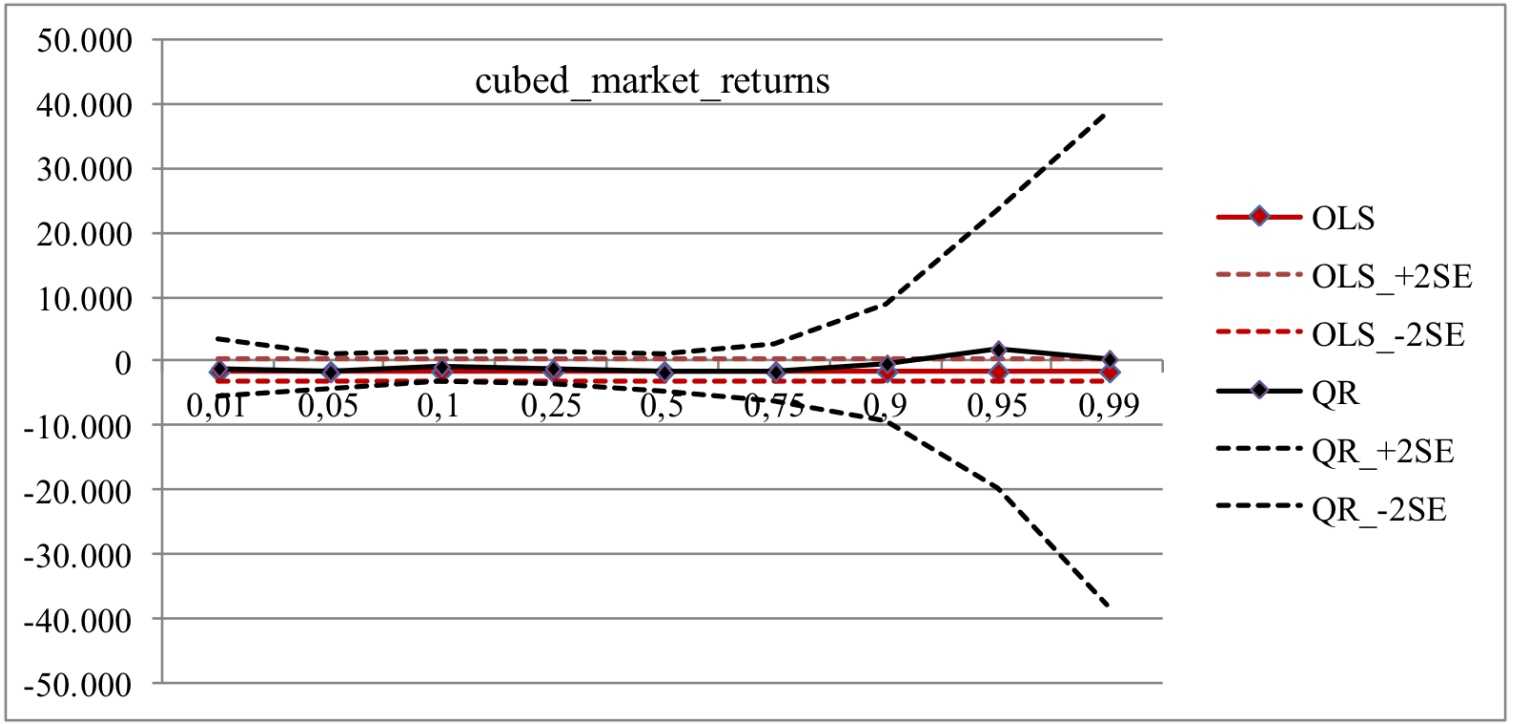

Figure 10: Comparison of estimated values of parameter $\hat{\beta}_{4}$ from model (6), OLS vs. QR method

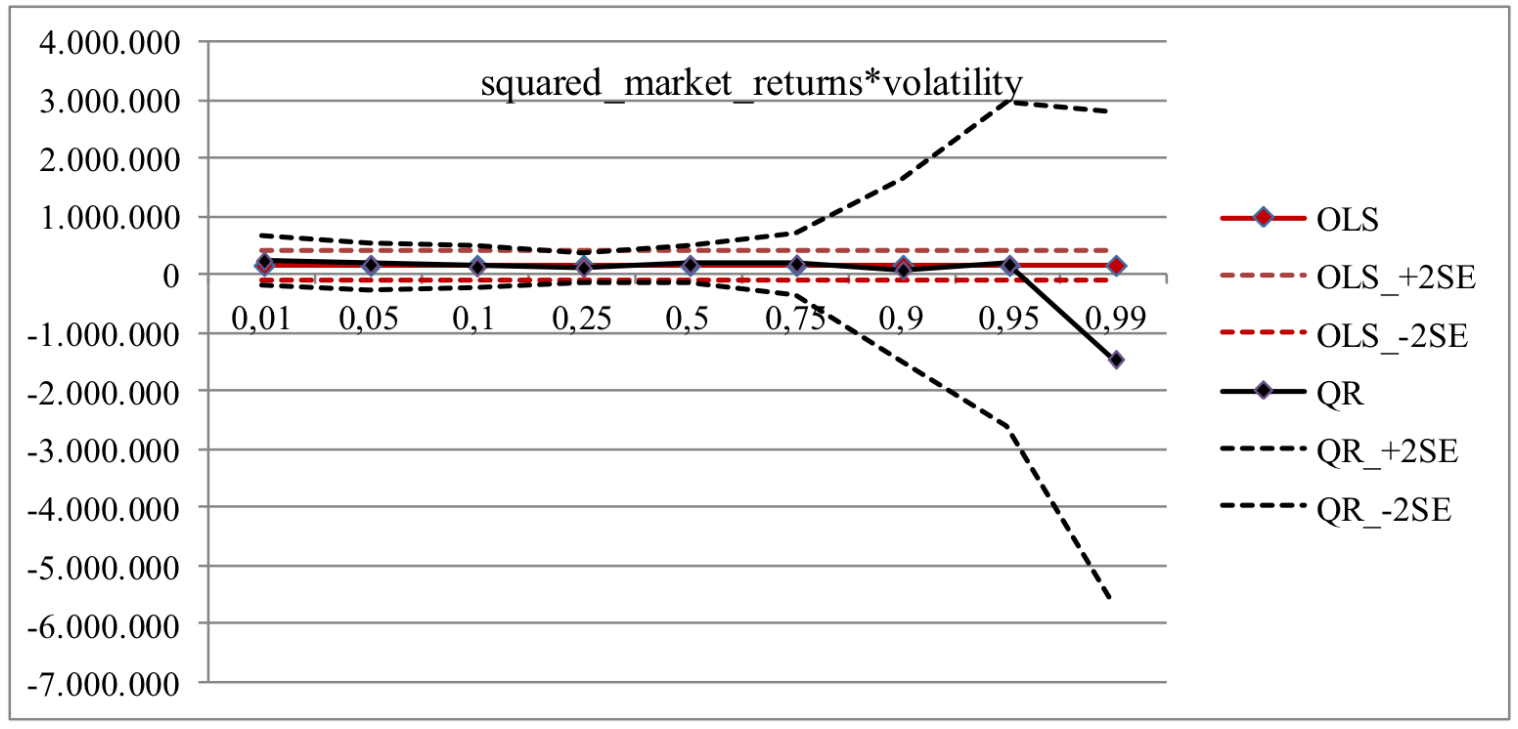


Figure 11: Comparison of estimated values of parameter $\hat{\beta}_{1}$ from model (7), OLS vs. QR method

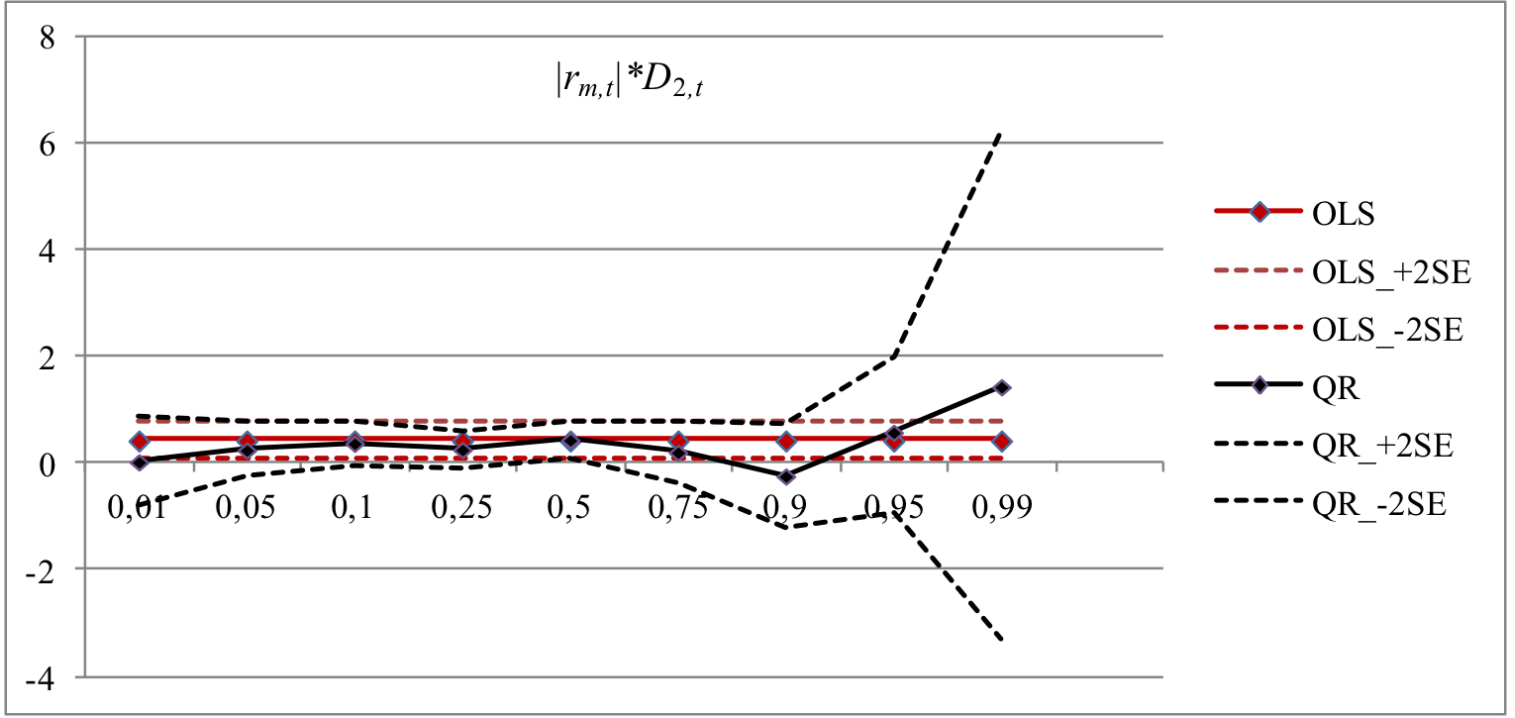

Figure 12: Comparison of estimated values of parameter $\hat{\phi}_{1}$ from model (7), OLS vs. QR method

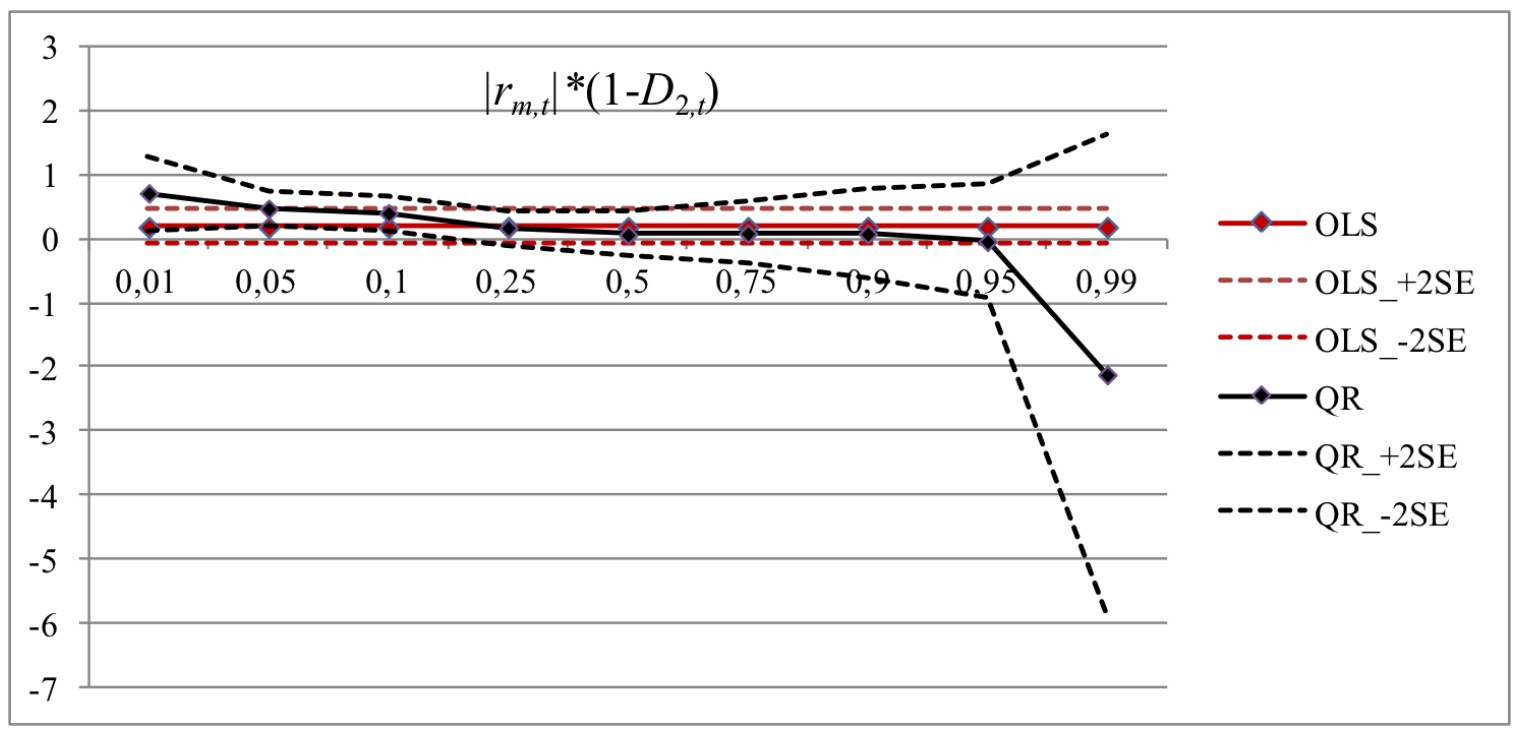


Figure 13: Comparison of estimated values of parameter $\hat{\gamma}_{1}$ from model (7), OLS vs. QR method

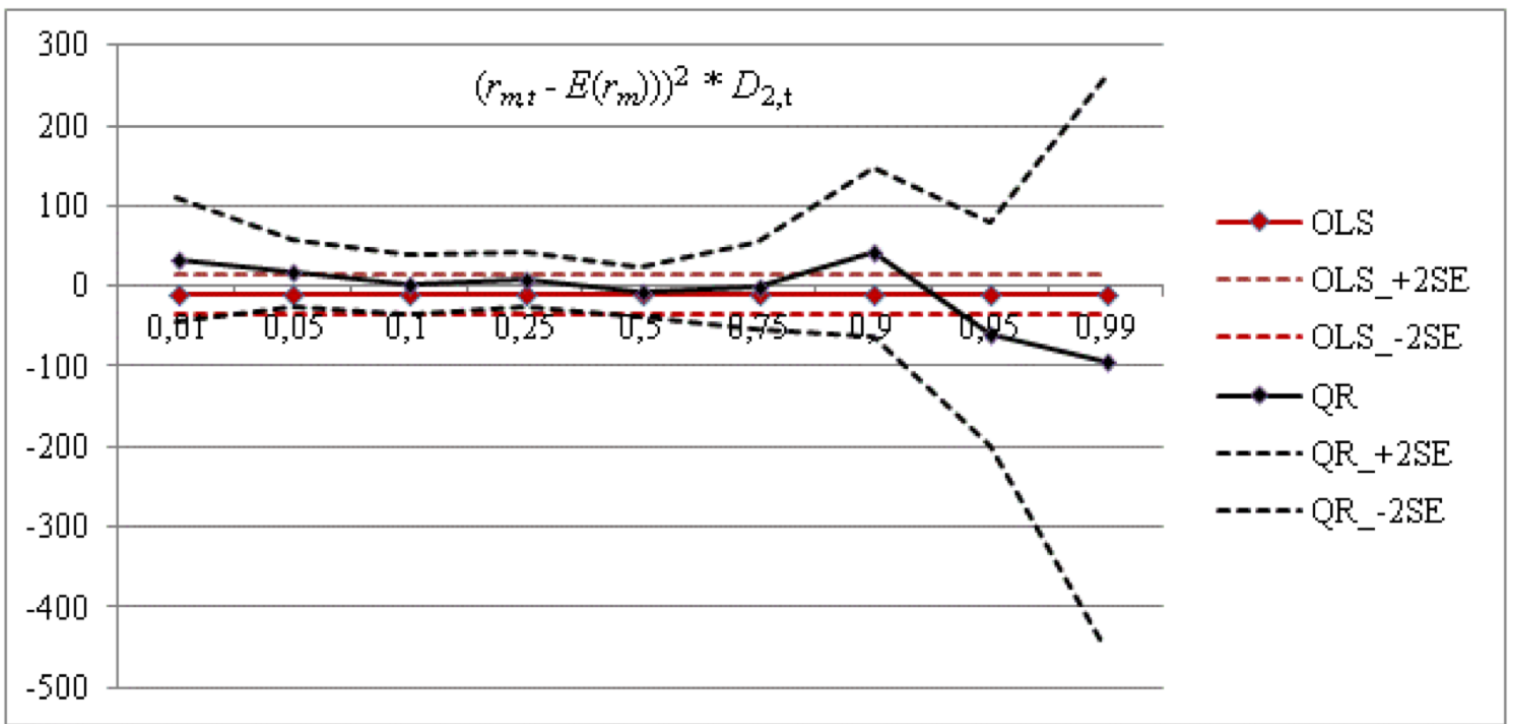

Figure 14: Comparison of estimated values of parameter $\hat{\phi}_{2}$ from model (7), OLS vs. QR method

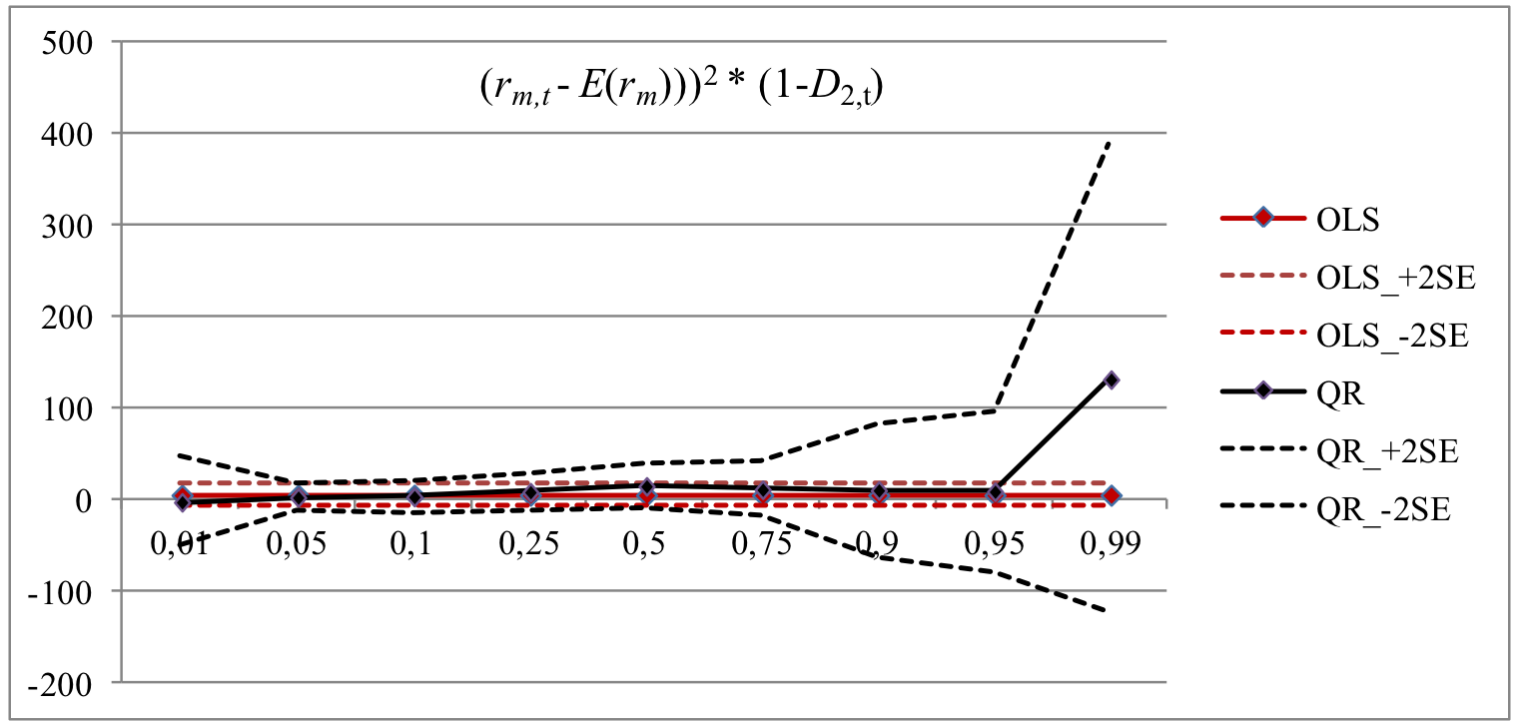


Figure 15: Comparison of estimated values of parameter $\hat{\gamma}_{2}$ from model (7), OLS vs. QR method

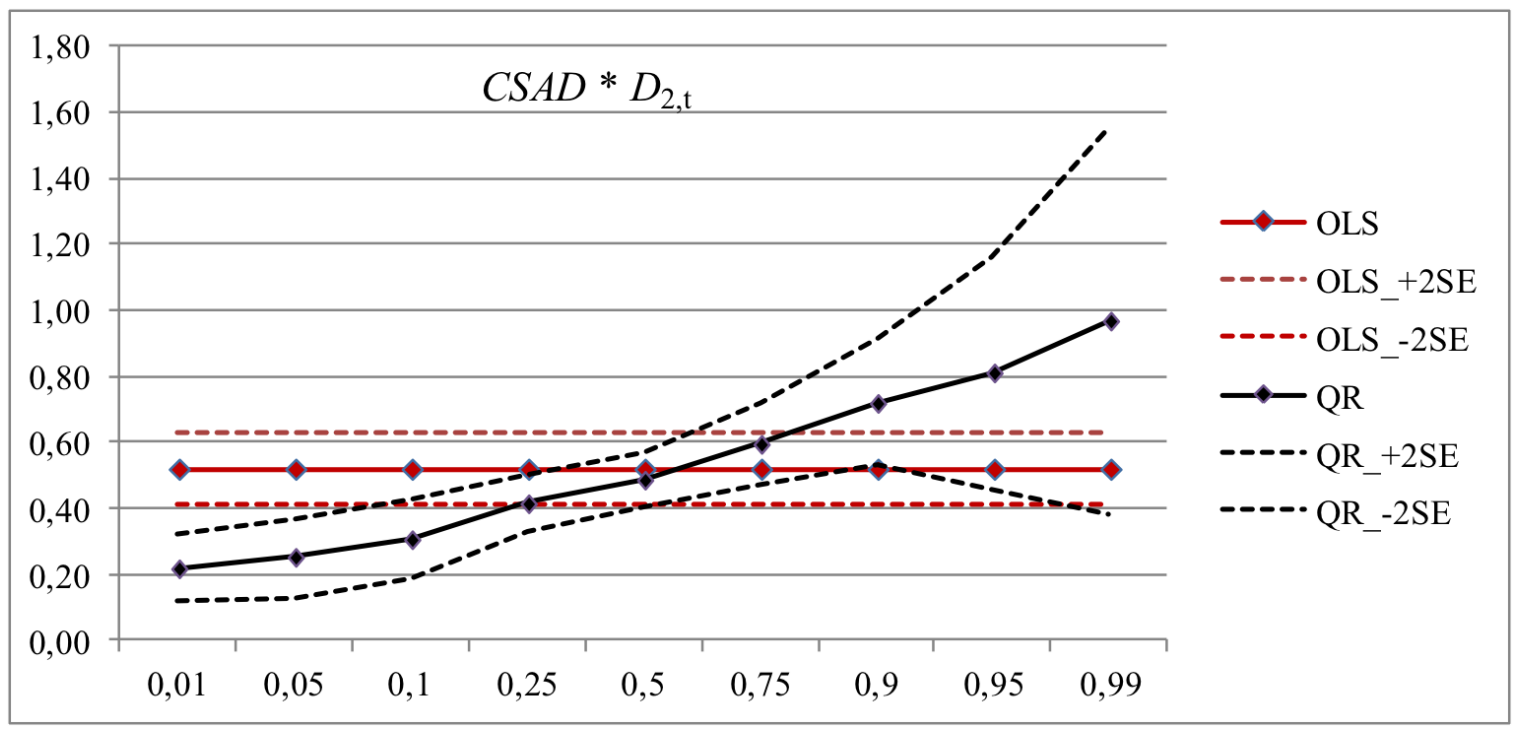

Figure 16: Comparison of estimated values of parameter $\hat{\phi}_{3}$ from model (7), OLS vs. QR method

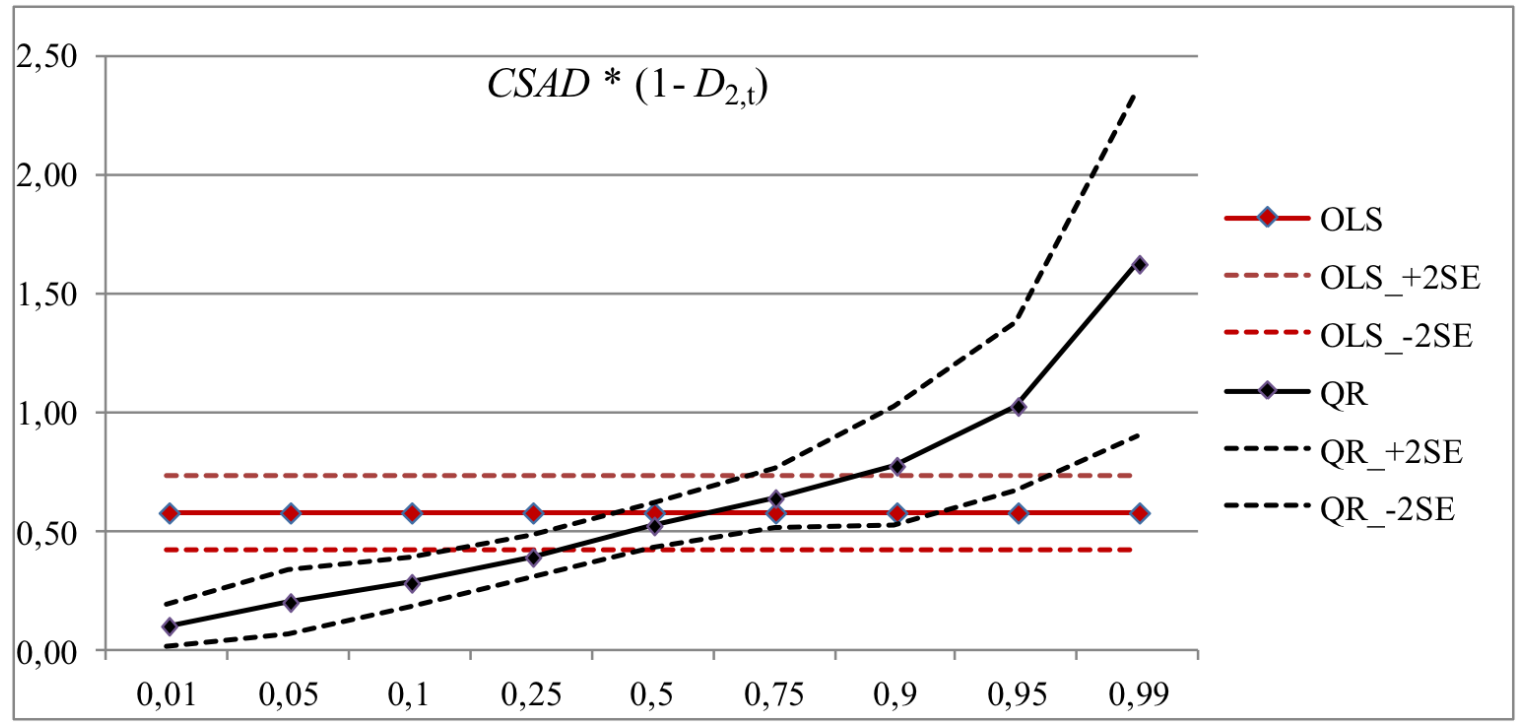




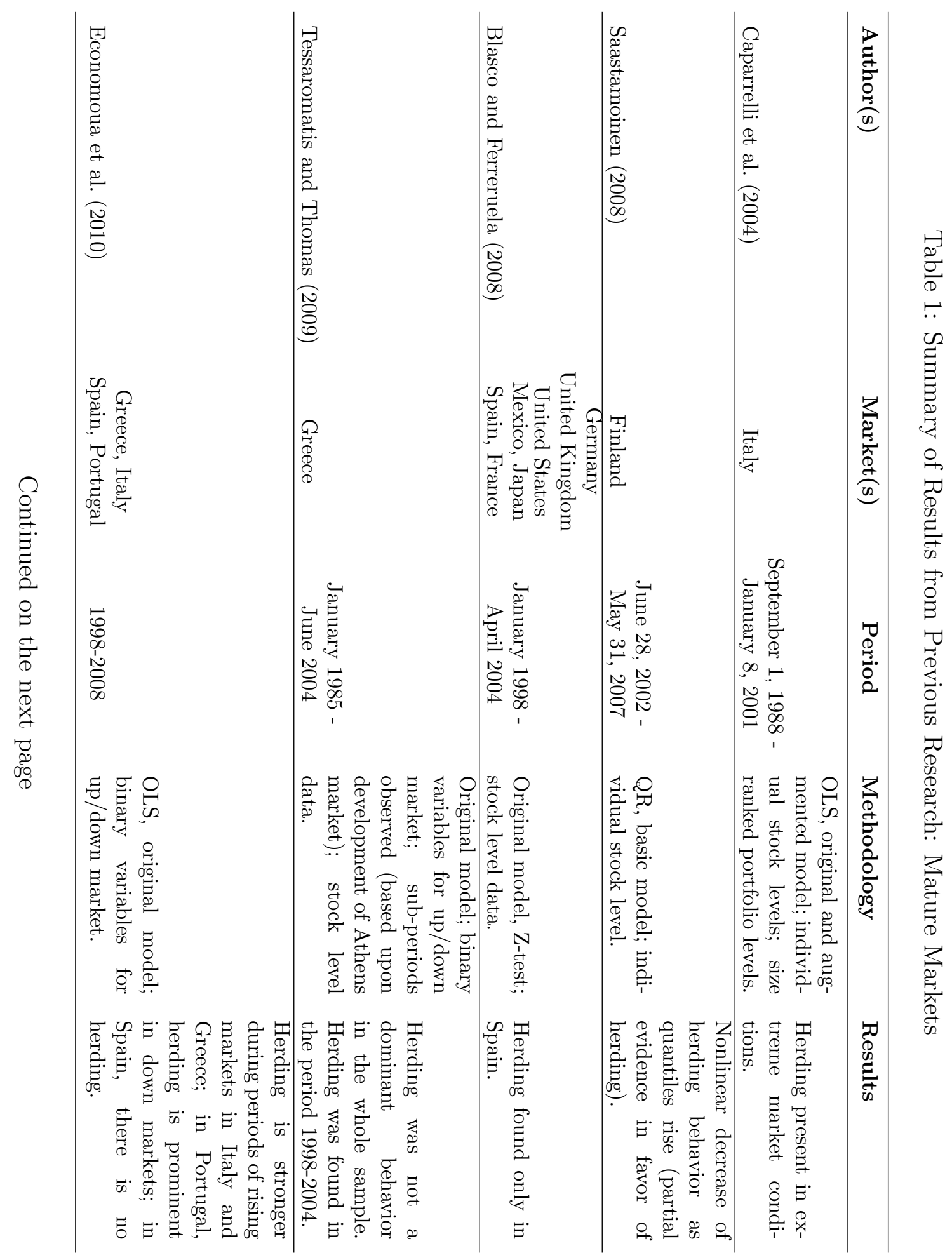




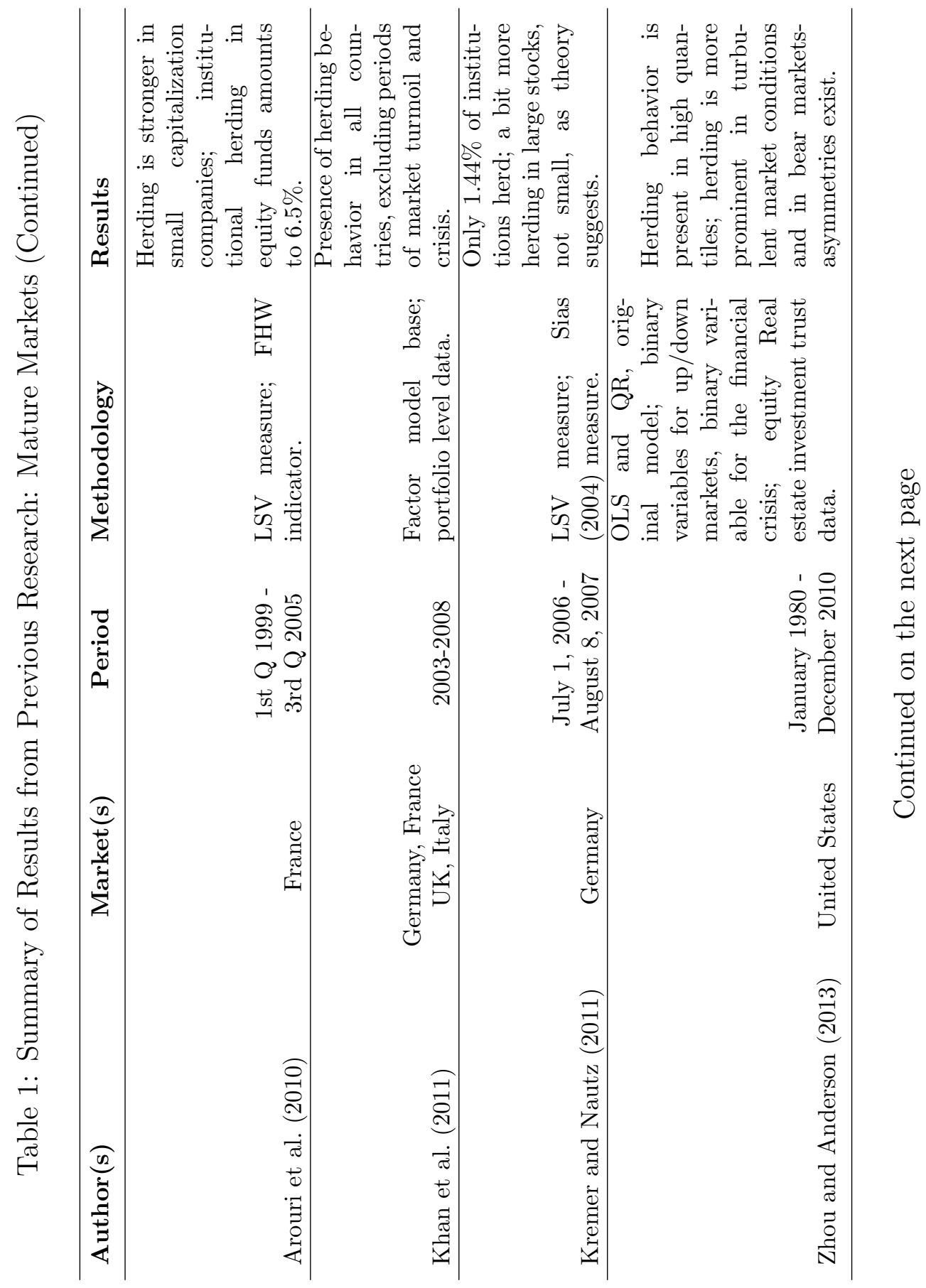




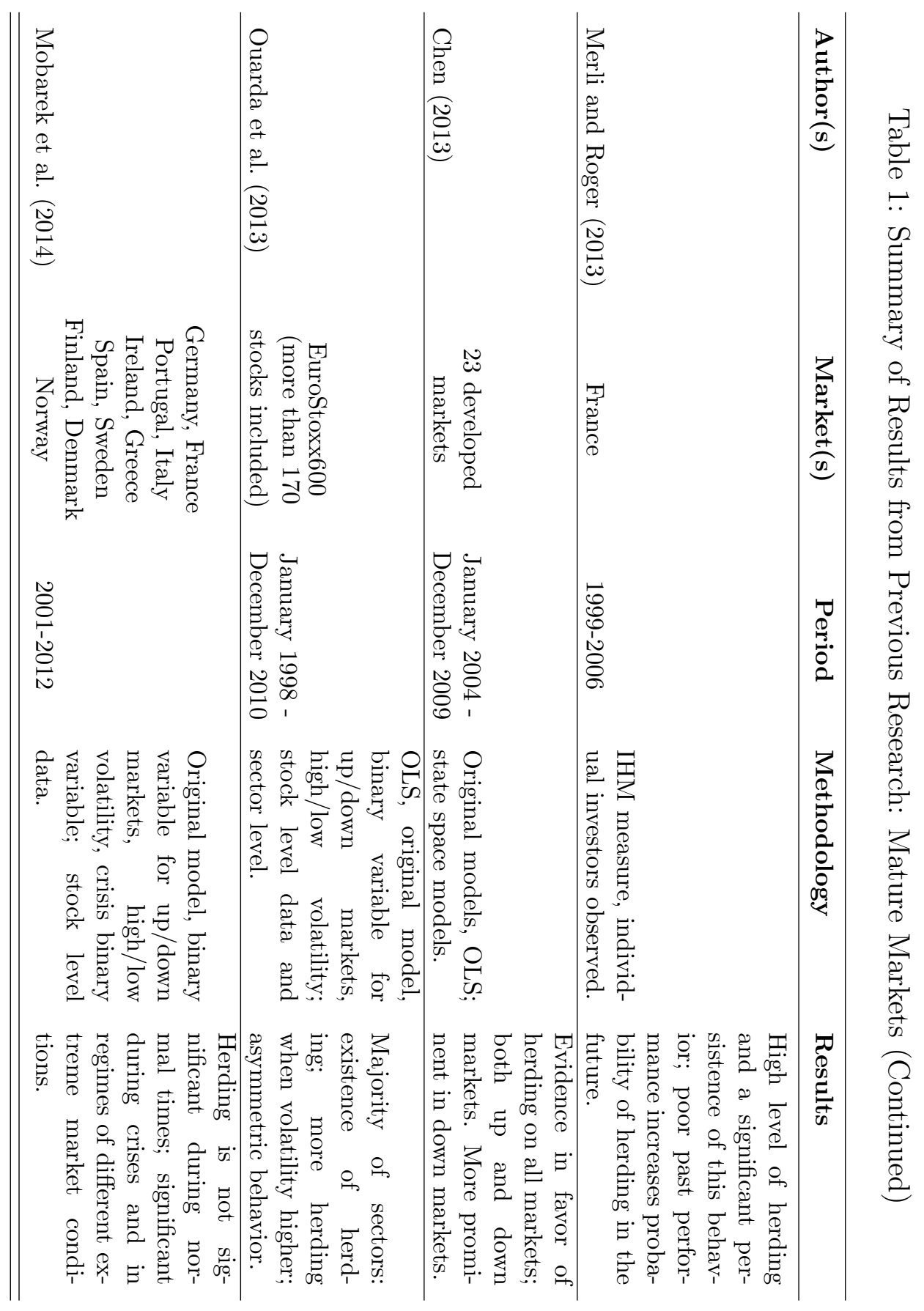




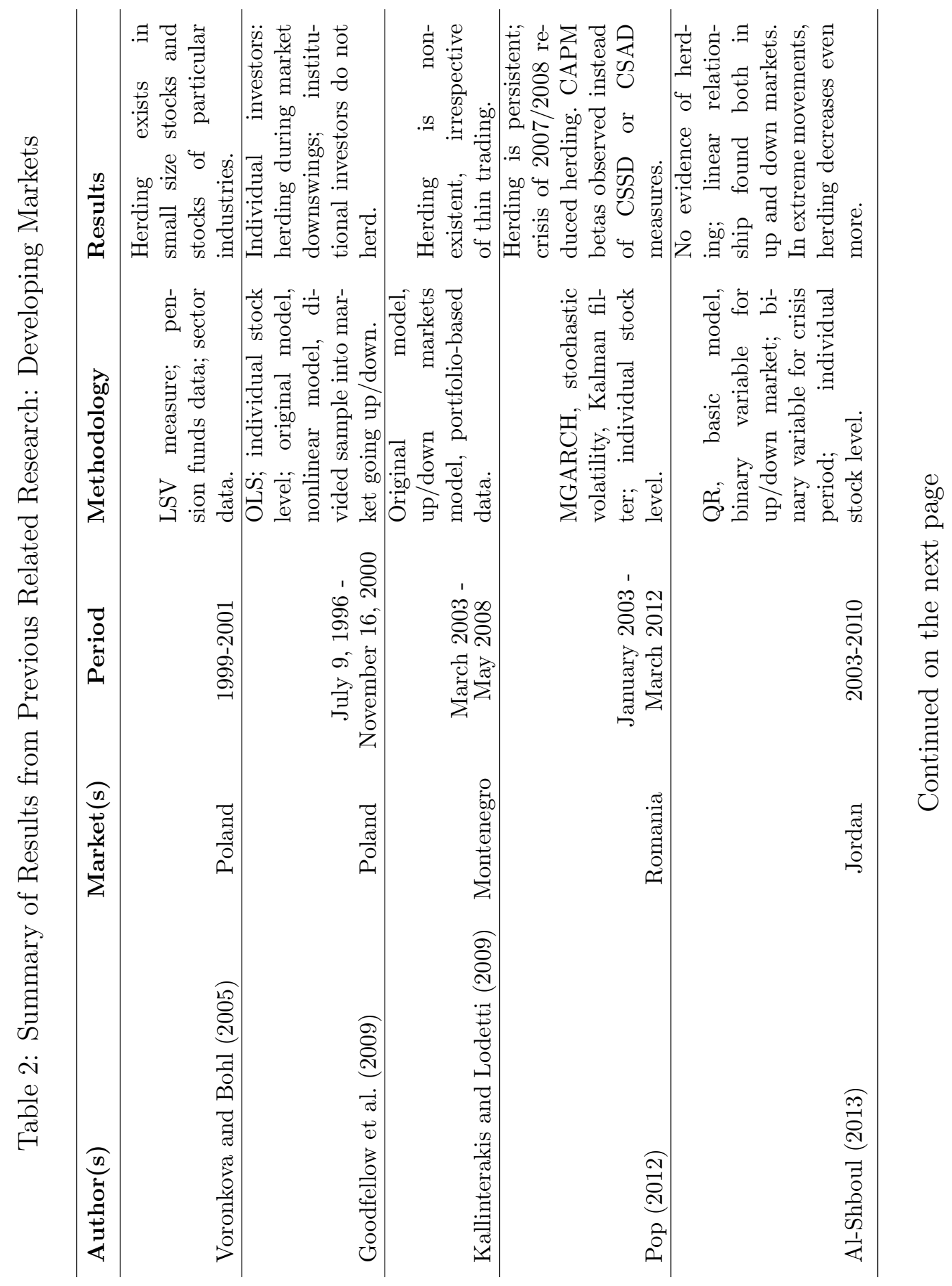




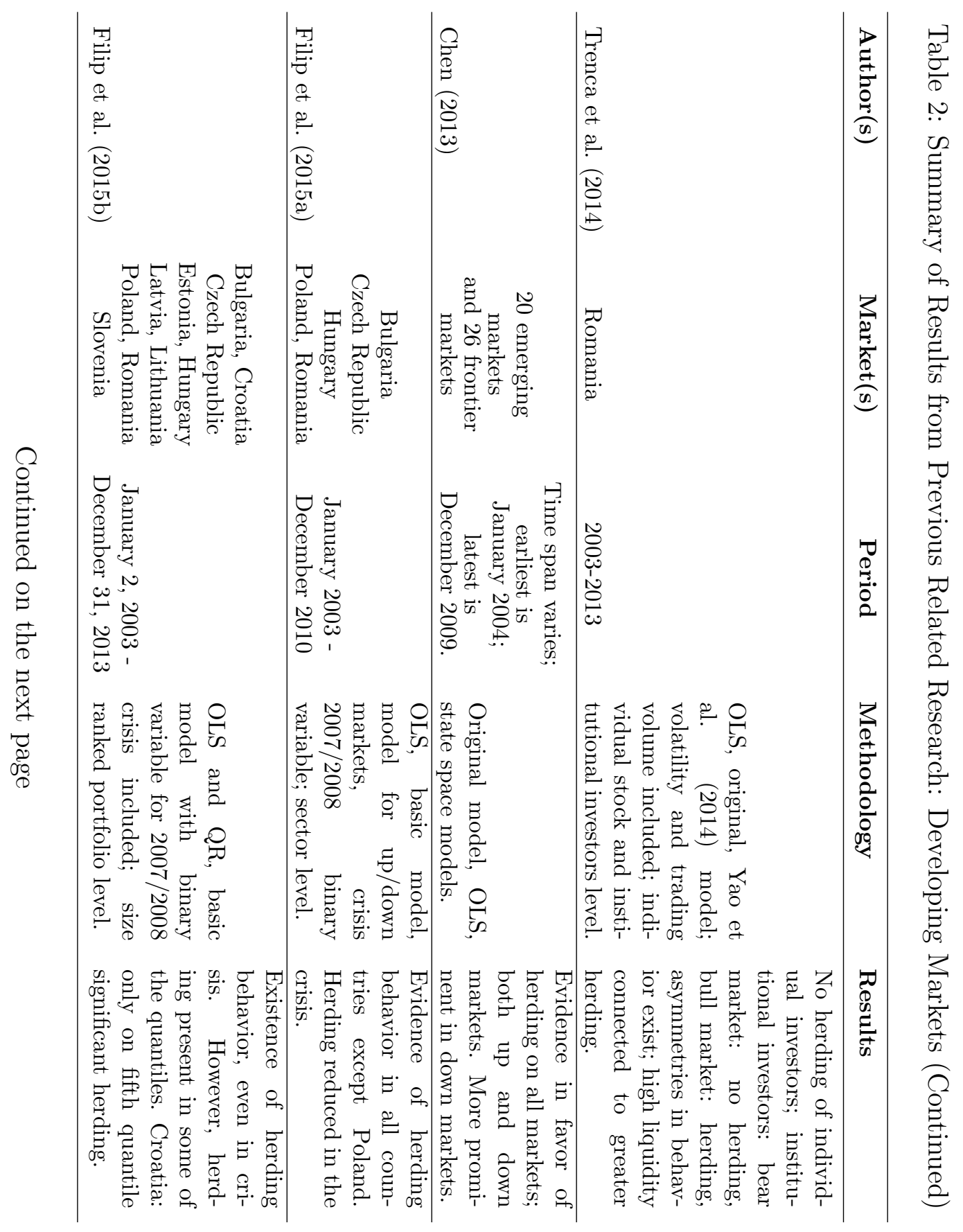




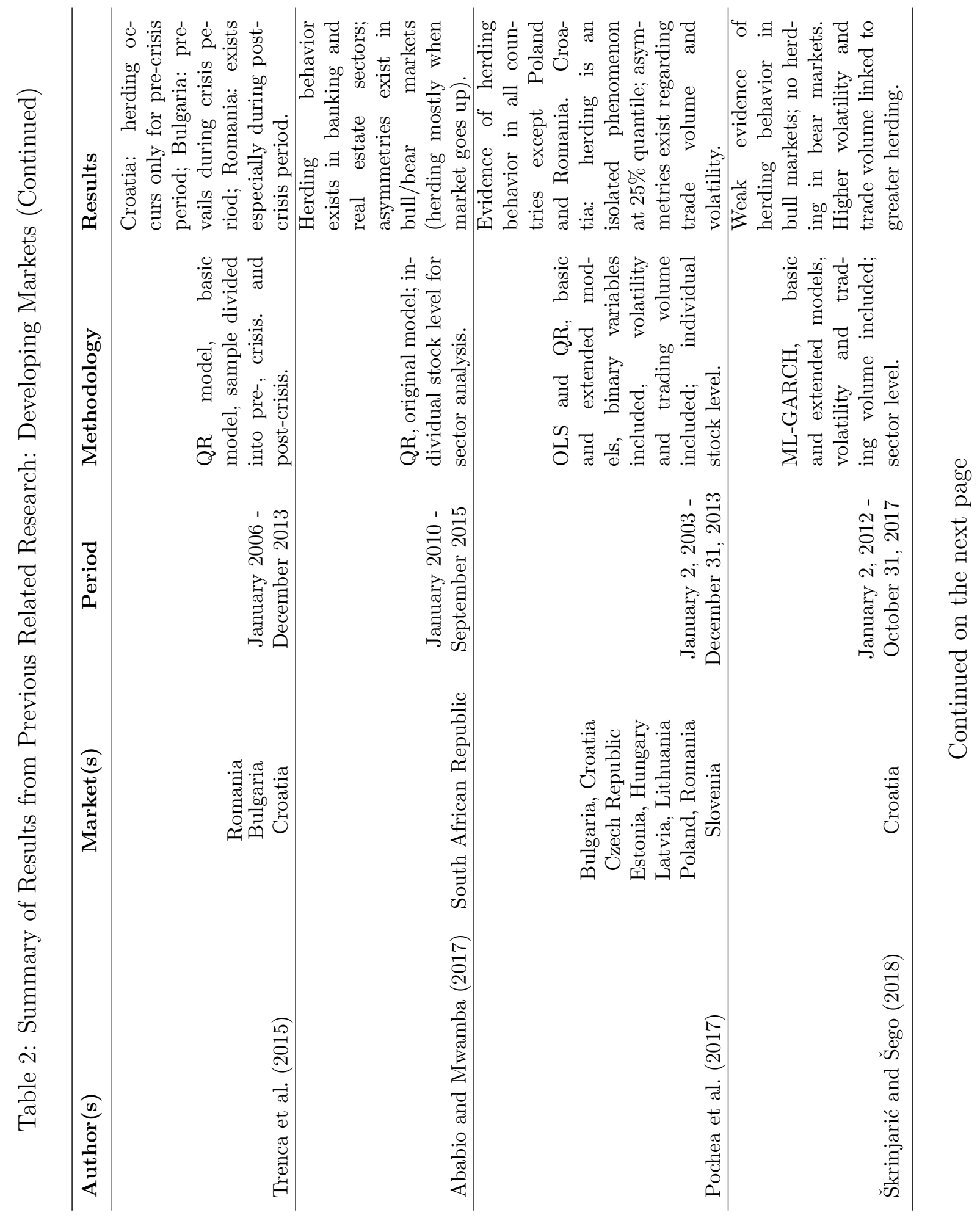




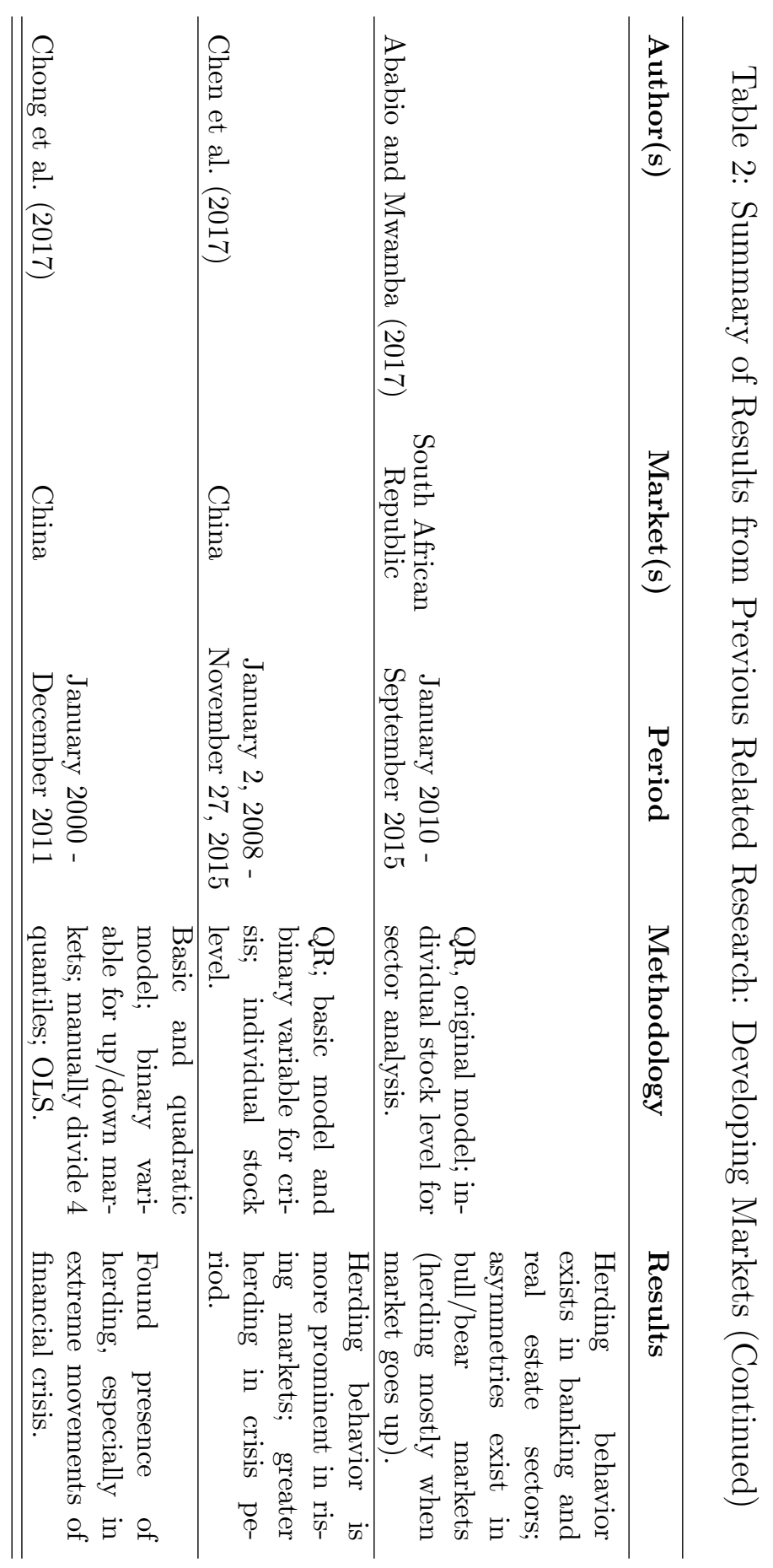




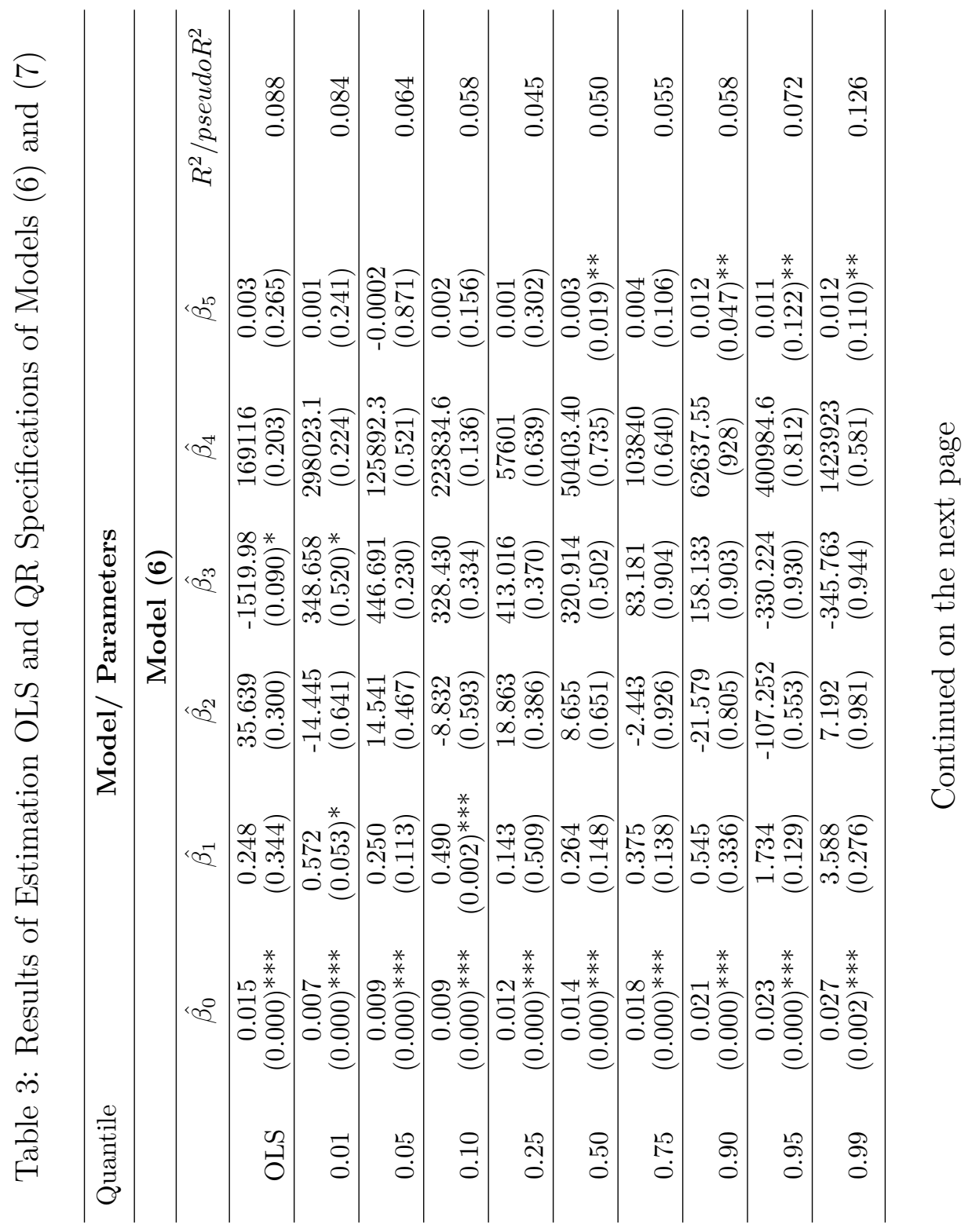




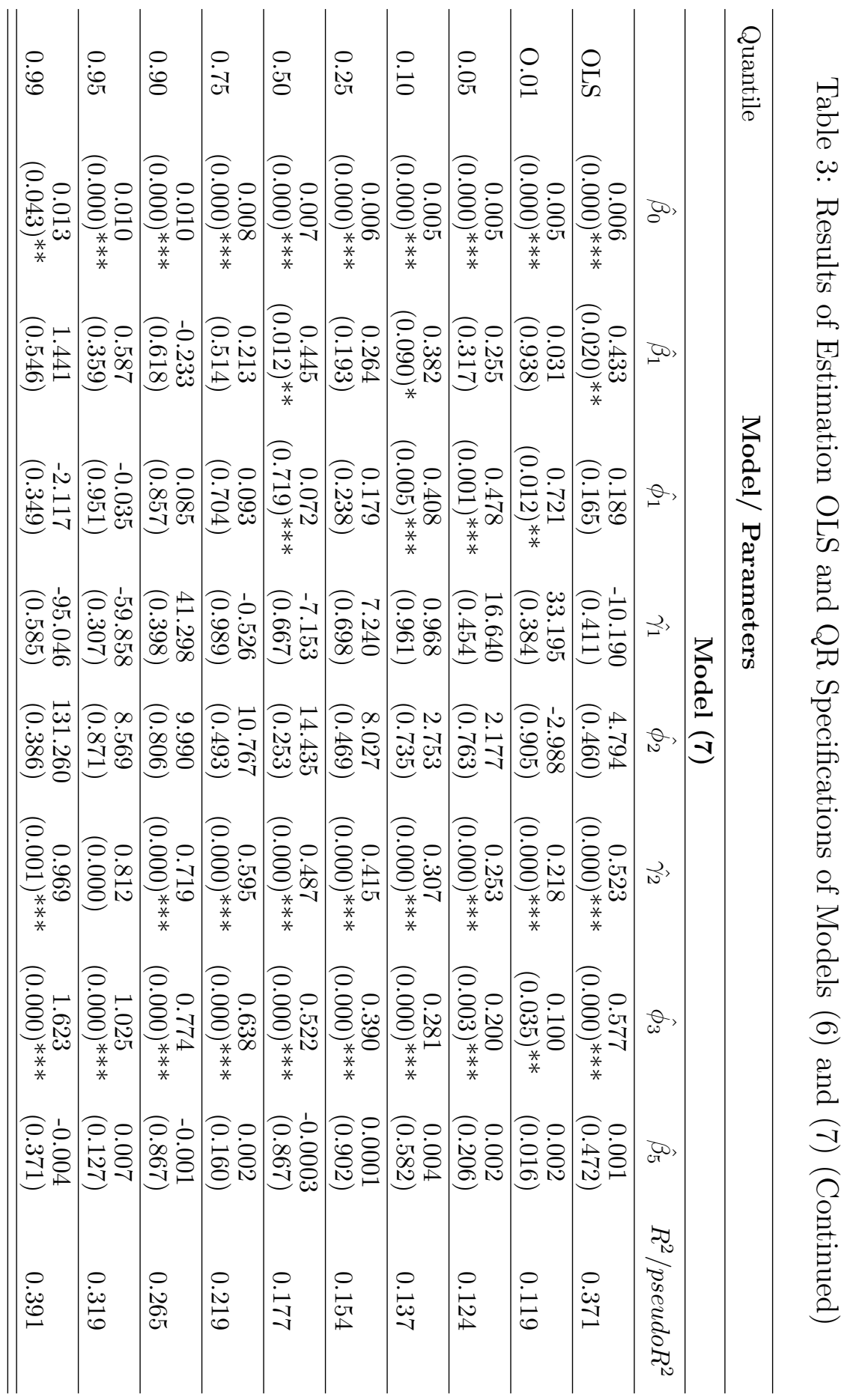


Table 4: Wald Test Results for Equality of Parameters of the Lagged Value of CSAD Variable in Model (7)

\begin{tabular}{cc}
\hline Quantile & Test value (p-value) \\
\hline 0.01 & $5.96(0.015)^{* *}$ \\
0.05 & $1.09(0.296)$ \\
0.10 & $0.41(0.523)$ \\
0.25 & $0.67(0.413)$ \\
0.50 & $1.11(0.293)$ \\
0.75 & $0.72(0.396)$ \\
0.90 & $0.31(0.579)$ \\
0.95 & $3.04(0.081)^{*}$ \\
0.99 & $3.65(0.056)^{* *}$ \\
\hline \hline
\end{tabular}

Table 5: Results of Estimation OLS and QR Specifications of Model (11)

\begin{tabular}{ccccccc}
\hline & $\hat{\beta}_{0}$ & $\hat{\beta}_{1}$ & $\hat{\beta}_{2}$ & $\hat{\beta}_{5}$ & $\hat{\lambda}_{4}$ & $R^{2} /$ pseudoR \\
\hline \multirow{2}{*}{ OLS } & 0.015 & 0.300 & 23.078 & 0.004 & -17.541 & \\
& $(0.000)^{* * *}$ & $(0.153)$ & $(0.418)$ & $(0.128)$ & $(0.487)$ & 0.082 \\
0.01 & 0.006 & 0.758 & -31.431 & 0.001 & 29.164 & \\
& $(0.000)^{* * *}$ & $(0.007)$ & $(0.266)$ & $(0.450)$ & $(0.103)$ & 0.080 \\
0.05 & 0.008 & 0.424 & -5.195 & -0.0003 & 12.295 & \\
& $(0.000)^{* * *}$ & $(0.038)$ & $(0.833)$ & $(0.844)$ & $(0.493)$ & 0.053 \\
0.10 & 0.009 & 0.527 & -6.823 & 0.001 & 9.213 & \\
& $(0.000)^{* * *}$ & $(0.005)^{* * *}$ & $(0.738)$ & $(0.637)$ & $(0.551)$ & 0.051 \\
0.25 & 0.012 & 0.281 & 3.515 & 0.001 & 3.499 & \\
& $(0.000)^{* * *}$ & $(0.216)$ & $(0.870)$ & $(0.461)$ & $(0.818)$ & 0.036 \\
0.50 & $(0.000)^{* * *}$ & $(0.238)$ & 16.005 & 0.003 & -6.390 & \\
& 0.017 & 0.343 & 2.842 & $(0.026)$ & $(0.627)$ & 0.042 \\
0.75 & $(0.000)^{* * *}$ & $(0.184)$ & $(0.910)$ & $(0.285)$ & $(0.746)$ & 0.047 \\
& 0.021 & 0.504 & -15.250 & 0.012 & -2.330 & \\
0.90 & $(0.000)^{* * *}$ & $(0.568)$ & $(0.920$ & $(0.086)$ & $(0.985)$ & 0.054 \\
& 0.024 & -0.159 & 288.288 & 0.017 & -290.938 & \\
0.95 & $(0.000)^{* * *}$ & $(0.877)$ & $(0.112)$ & $(0.037)^{* *}$ & $(0.060)^{*}$ & 0.085 \\
& 0.030 & 2.463 & 57.111 & 0.003 & 6.460 & \\
0.99 & $(0.000)^{* * *}$ & $(0.474)$ & $(0.845)$ & $(0.285)$ & $(0.746)$ & 0.047 \\
\hline \hline
\end{tabular}


Table 6: Results of Estimation OLS and QR Specifications of Model (12)

\begin{tabular}{|c|c|c|c|c|c|c|c|c|}
\hline & $\hat{\beta_{0}}$ & $\hat{\beta_{1}}$ & $\hat{\beta}_{2}$ & $\hat{\beta_{3}}$ & $\hat{\beta}_{4}$ & $\hat{\beta}_{5}$ & $\lambda$ & $R^{2} /$ pseudoR $R^{2}$ \\
\hline OLS & $\begin{array}{c}0.015 \\
(0.000)^{* * *}\end{array}$ & $\begin{array}{c}0.304 \\
(0.171)\end{array}$ & $\begin{array}{l}20.613 \\
(0.444)\end{array}$ & $\begin{array}{c}189.565 \\
(0.322)\end{array}$ & $\begin{array}{l}189808.7 \\
(0.054)^{* *}\end{array}$ & $\begin{array}{c}0.004 \\
(0.099)^{*}\end{array}$ & $\begin{array}{l}-28.753 \\
(0.312)\end{array}$ & 0.083 \\
\hline 0.01 & $\begin{array}{c}0.006 \\
(0.000)^{* * *}\end{array}$ & $\begin{array}{c}0.755 \\
(0.015)^{* *}\end{array}$ & $\begin{array}{l}-28.148 \\
(0.394)\end{array}$ & $\begin{array}{c}371.381 \\
(0.569)\end{array}$ & $\begin{array}{c}78554.63 \\
(0.758)\end{array}$ & $\begin{array}{c}0.001 \\
(0.421)\end{array}$ & $\begin{array}{l}30.488 \\
(0.278)\end{array}$ & 0.082 \\
\hline 0.05 & $\begin{array}{c}0.008 \\
(0.000)^{* * *}\end{array}$ & $\begin{array}{c}0.348 \\
(0.085)^{*}\end{array}$ & $\begin{array}{c}3.751 \\
(0.882)\end{array}$ & $\begin{array}{c}466.490 \\
(0.353)\end{array}$ & $\begin{array}{c}-23530.57 \\
(0.896)^{* *}\end{array}$ & $\begin{array}{c}-0.0003 \\
(0.830)\end{array}$ & $\begin{array}{l}23.087 \\
(0.326)\end{array}$ & 0.056 \\
\hline 0.10 & $\begin{array}{c}0.009 \\
(0.000)^{* * *}\end{array}$ & $\begin{array}{c}0.535 \\
(0.005)\end{array}$ & $\begin{array}{l}-12.362 \\
(0.555)\end{array}$ & $\begin{array}{c}359.069 \\
(0.453)\end{array}$ & $\begin{array}{c}10666.6 \\
(0.756)\end{array}$ & $\begin{array}{c}0.002 \\
(0.366)\end{array}$ & $\begin{array}{l}15.475 \\
(0.278)\end{array}$ & 0.054 \\
\hline 0.25 & $\begin{array}{c}0.012 \\
(0.000)^{* * *}\end{array}$ & $\begin{array}{c}0.247 \\
(0.348)\end{array}$ & $\begin{array}{c}8.393 \\
(0.764)\end{array}$ & $\begin{array}{c}388.482 \\
(0.443)\end{array}$ & $\begin{array}{c}83995.07 \\
(0.537)\end{array}$ & $\begin{array}{c}0.001 \\
(0.484)\end{array}$ & $\begin{array}{c}4.165 \\
(0.833)\end{array}$ & 0.038 \\
\hline 0.50 & $\begin{array}{c}0.009 \\
(0.000)^{* * *}\end{array}$ & $\begin{array}{c}0.535 \\
(0.005)^{* * *}\end{array}$ & $\begin{array}{l}12.362 \\
(0.555)\end{array}$ & $\begin{array}{c}359.069 \\
(0.453)\end{array}$ & $\begin{array}{c}10666.6 \\
(0.756)\end{array}$ & $\begin{array}{c}0.002 \\
(0.366)\end{array}$ & $\begin{array}{l}15.475 \\
(0.278)\end{array}$ & 0.054 \\
\hline 0.75 & $\begin{array}{c}0.017 \\
(0.000)^{* * *}\end{array}$ & $\begin{array}{c}0.350 \\
(0.200)\end{array}$ & $\begin{array}{l}-0.619 \\
(0.984)\end{array}$ & $\begin{array}{l}97.955 \\
(0.900)\end{array}$ & $\begin{array}{c}178601.6 \\
(0.625)\end{array}$ & $\begin{array}{c}0.004 \\
(0.257)\end{array}$ & $\begin{array}{l}-9.763 \\
(0.761)\end{array}$ & 0.048 \\
\hline 0.90 & $\begin{array}{c}0.021 \\
(0.000)^{* * *}\end{array}$ & $\begin{array}{l}0.458 \\
(0.604)\end{array}$ & $\begin{array}{c}-16.002 \\
(0.915)\end{array}$ & $\begin{array}{l}21.850 \\
(0.989)\end{array}$ & $\begin{array}{c}82859.76 \\
(0.921)\end{array}$ & $\begin{array}{c}0.012 \\
(0.098)^{*}\end{array}$ & $\begin{array}{l}-9.513 \\
(0.401)\end{array}$ & 0.052 \\
\hline 0.95 & $\begin{array}{c}0.024 \\
(0.000)^{* * *}\end{array}$ & $\begin{array}{l}-0.257 \\
(0.844)\end{array}$ & $\begin{array}{c}300.202 \\
(0.144)\end{array}$ & $\begin{array}{c}385.910 \\
(0.893)\end{array}$ & $\begin{array}{c}34005.76 \\
(0.986)\end{array}$ & $\begin{array}{c}0.014 \\
(0.055)^{*}\end{array}$ & $\begin{array}{c}-290.641 \\
(0.058)\end{array}$ & 0.084 \\
\hline 0.99 & $\begin{array}{c}0.027 \\
(0.003)^{* * *}\end{array}$ & $\begin{array}{c}3.741 \\
(0.313)\end{array}$ & $\begin{array}{c}-90.462 \\
(0.799)\end{array}$ & $\begin{array}{c}-2144.11 \\
(0.614)\end{array}$ & $\begin{array}{c}2109908 \\
(0.453)\end{array}$ & $\begin{array}{c}0.011 \\
(0.146)\end{array}$ & $\begin{array}{c}-255.903 \\
(0.105)\end{array}$ & 0.138 \\
\hline
\end{tabular}




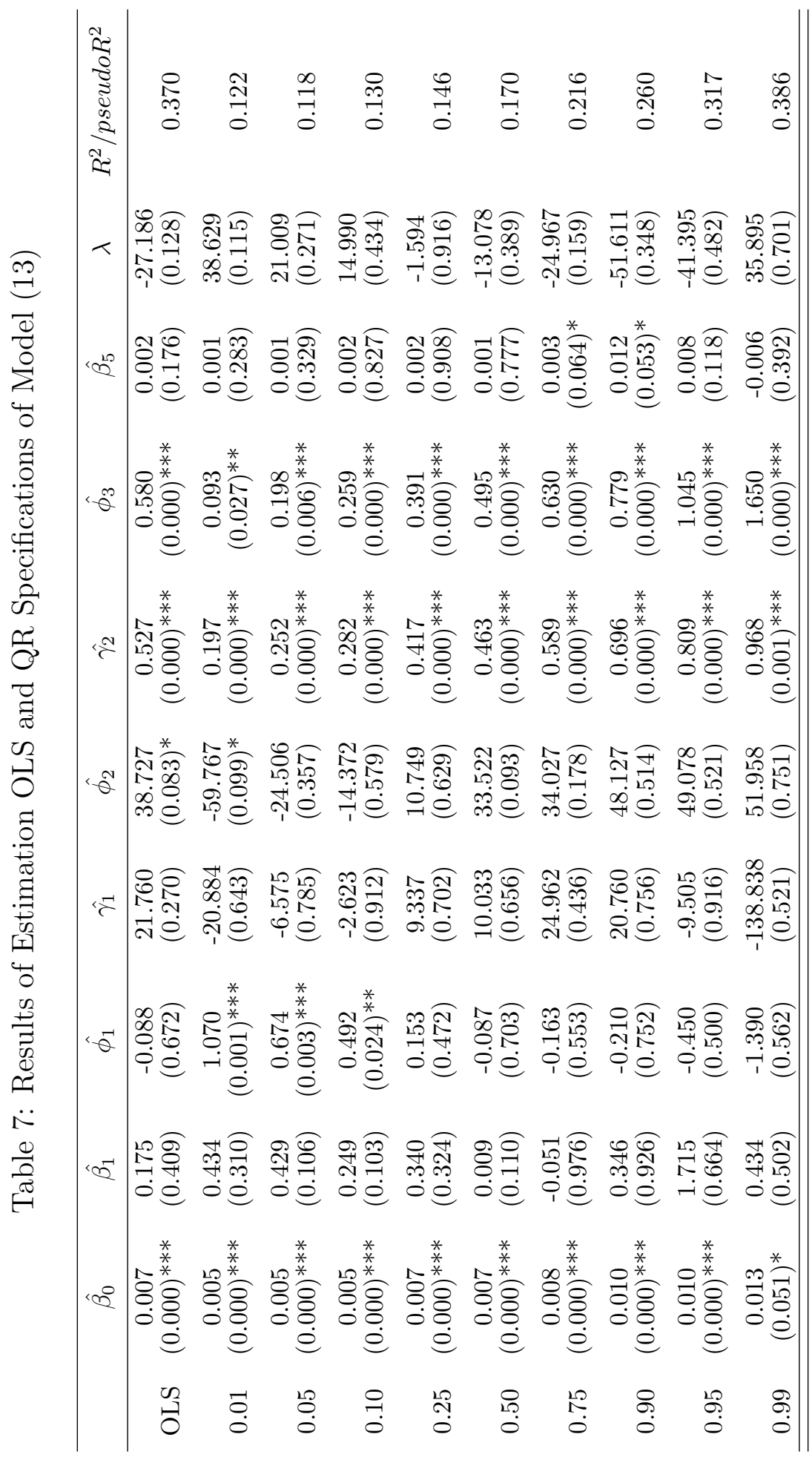


Table 8: Results of Estimation of OLS and QR Specification of Model

\begin{tabular}{cccccc}
\hline Quantile & $\hat{\beta_{0}}$ & $\hat{\beta}_{1}$ & $\hat{\beta}_{2}$ & $\hat{\beta}_{5}$ & $R^{2} /$ pseudoR \\
\hline \multirow{2}{*}{ OLS } & 0.0149 & 0.4757 & 1.3994 & 0.0032 & \\
& $(0.000)^{* * *}$ & $(0.040)^{* *}$ & $(0.867)$ & $(0.191)$ & 0.0844 \\
0.01 & 0.0071 & 0.2909 & 11.241 & 0.0009 & \\
& $(0.000)^{* * *}$ & $(0.136)$ & $(0.434)$ & $(0.298)$ & 0.0804 \\
0.05 & 0.0084 & 0.3133 & 10.327 & -0.0002 & \\
& $(0.000)^{* * *}$ & $(0.010)^{* *}$ & $(0.290)$ & $(0.882)$ & 0.0560 \\
0.10 & 0.0091 & 0.3915 & 5.1215 & 0.0021 & \\
& $(0.000)^{* * *}$ & $(0.004)^{* * *}$ & $(0.585)$ & $(0.150)$ & 0.0545 \\
0.25 & 0.0116 & 0.2409 & 7.9924 & 0.0015 & \\
& $(0.000)^{* * *}$ & $(0.082)$ & $(0.403)$ & $(0.224)$ & 0.0403 \\
0.50 & 0.0142 & 0.2919 & 7.0272 & 0.0033 & \\
& $(0.000)^{* * *}$ & $(0.046)^{* *}$ & $(0.488)$ & $(0.020)^{* *}$ & 0.0456 \\
0.75 & 0.0175 & 0.2441 & 12.449 & 0.0039 & \\
& $(0.000)^{* * *}$ & $(0.227)$ & $(0.315)$ & $(0.099)^{*}$ & 0.0511 \\
0.90 & 0.0214 & 0.5265 & -18.449 & 0.0122 & \\
& $(0.000)^{* * *}$ & $(0.087)^{*}$ & $(0.427$ & $(0.026)^{* *}$ & 0.0577 \\
0.95 & 0.0237 & 1.2682 & -44.239 & 0.0113 & \\
& $(0.000)^{* * *}$ & $(0.134)$ & $(0.653)$ & $(0.119)$ & 0.0701 \\
0.99 & 0.0274 & 3.6763 & -19.985 & 0.0105 & \\
\hline \hline
\end{tabular}

